\title{
Fabrication of Small-Orifice Fuel Injectors for Diesel Engines
}

Energy Technology Division

Argonne National Laboratory 


\section{About Argonne National Laboratory}

Argonne is operated by The University of Chicago for the U.S. Department of Energy Office of Science, under contract W-31-109-Eng-38. The Laboratory's main facility is outside Chicago, at 9700 South Cass Avenue, Argonne, Illinois 60439. For information about Argonne and its pioneering science and technology programs, see www.anl.gov.

\section{Availability of This Report}

This report is available, at no cost, at http://www.osti.gov/bridge. It is also available on paper to U.S. Department of Energy and its contractors, for a processing fee, from:

U.S. Department of Energy

Office of Scientific and Technical Information

P.O. Box 62

Oak Ridge, TN 37831-0062

phone (865) 576-8401

fax (865) 576-5728

reports@adonis.osti.gov

\section{Disclaimer}

This report was prepared as an account of work sponsored by an agency of the United States Government. Neither the United States Government nor any agency thereof, nor The University of Chicago, nor any of their employees or officers, makes any warranty, express or implied, or assumes any legal liability or responsibility for the accuracy, completeness, or usefulness of any information, apparatus, product, or process disclosed, or represents that its use would not infringe privately owned rights. Reference herein to any specific commercial product, process, or service by trade name, trademark, manufacture, or otherwise, does not necessarily constitute or imply its endorsement, recommendation, or favoring by the United States Government or any agency thereof. The views and opinions of document authors expressed herein do not necessarily state or reflect those of the United States Government or any agency thereof, -Argonne National Laboratory, or The University of Chicago. 
ANL-05/06

\title{
Fabrication of Small-Orifice Fuel Injectors for Diesel Engines* \\ by
}

\author{
J. B. Woodford and G. R. Fenske \\ Energy Technology Division \\ Argonne National Laboratory, \\ Argonne, IL 60439-4838, USA
}

March 2005

\begin{abstract}
The submitted manuscript has been authored by a contractor of the U. S. Government under Contract No. W-31-109-ENG-38. Accordingly, the U. S. Government retains a nonexclusive, royalty-free license to publish or reproduce the published form of this contribution, or allow others to do so, for U. S. Government purposes.
\end{abstract}

\begin{abstract}
ANL Report
*Work supported by the U. S. Department of Energy, Office of Transportation Technology under Contract W-31-109-ENG-38.
\end{abstract}




\begin{abstract}
Diesel fuel injector nozzles with spray hole diameters of 50-75 $\mu \mathrm{m}$ have been fabricated via electroless nickel plating of conventionally made nozzles. Thick layers of nickel are deposited onto the orifice interior surfaces, reducing the diameter from $\sim 200 \mu \mathrm{m}$ to the target diameter. The nickel plate is hard, smooth, and adherent, and covers the orifice interior surfaces uniformly.
\end{abstract}

\title{
Introduction
}

In 2007, Environmental Protection Agency (EPA) regulations mandate diesel engine emission reductions to 0.01 grams of particulate matter (PM) per engine horsepower per hour and 0.2 grams of nitrogen oxides $\left(\mathrm{NO}_{\mathrm{x}}\right)$ per engine horsepower per hour. Further reductions are expected for 2010. To achieve these levels, research is being performed on engine design changes and aftertreatment devices. One design change under consideration is the reduction of the fuel injector orifice diameter.

Pickett and coworkers ${ }^{1,2}$ have shown elimination of soot in a test cylinder by reducing injector orifice diameter to $50 \mu \mathrm{m}$, even with high levels of exhaust gas recirculation and concomitant reduction in $\mathrm{NO}_{\mathrm{x}}$ emissions. EPA National Vehicle and Fuels Emission Laboratory (NVFEL) researchers have observed reduced PM emissions from a light-duty diesel engine equipped with 75 - $\mu \mathrm{m}$-diameter-orifice injector nozzles ${ }^{3}$. These reductions likely arise from increases in fuel atomization efficiency, leading to more complete combustion. ${ }^{4}$ Although injectors with $100 \mu \mathrm{m}$ diameter orifices can be economically produced using electric-discharge machining (EDM), further reductions in hole size are accompanied by unacceptable fabrication error rates at this point.

While reducing orifice diameter has the potential to reduce PM emissions, it leads to potential difficulties as well. Smaller orifices are more susceptible to partial or complete blockage by coking deposits. In addition, in its as-made state the interior of EDMfabricated orifices is extremely rough, and must be smoothed with abrasive slurry, a process called "hydroforming". The interaction between the fuel stream and the orifice wall forms a highly turbulent layer adjacent to the wall, reducing the effective area through which fuel can be delivered. Finally, achieving the desired effect reduction in orifice diameter in heavy truck engines - from ca. $200 \mu \mathrm{m}$ to ca. $50 \mu \mathrm{m}$ - requires redesigning the combustion chamber and bowl, together with some means of compensating for the drastic reduction in fuel delivered per injection cycle. Until an economical technique for fabricating small-orifice injectors is developed, no engine manufacturer will support this effort.

Although mechanical drilling and EDM are not suitable for producing such small holes, two other technologies may be used to directly manufacture them: laser drilling and LIGA, a lithographic technique known by its German acronym. Both technologies have disadvantages precluding their commercial use in the near- to mid-term. Although LIGA can be used to produce very small (ca. $1 \mu \mathrm{m}$ diameter) holes, it is a slow process; and laser drilling of small-diameter holes with high aspect ratio is difficult because of material redeposition on the hole walls during drilling. In the near term, therefore, another method must be found. 
A wide variety of techniques exist for the deposition of moderately thick $(>10 \mu \mathrm{m})$ films onto various surfaces. It may be possible to reduce the diameter of an extant orifice by depositing material onto the interior of the orifice (Fig. 1). Before initiating a laboratory study of this possibility, different coating methods were compared, to select appropriate candidate method(s) for experimental trials. By choosing an appropriate coating material and method, it may be possible to tailor the surface chemistry and morphology to minimize deposit formation and surface roughness.

To test this proposed method for small-orifice nozzle preparation, the following plan was devised:

1. Select an appropriate coating method.

2. Using this method, reduce orifice diameter to ca. $50 \mu \mathrm{m}$ in bench tests. If the bench trials fail, test another method (if possible).

3. Scale up the method.

4. Using the scaled-up method, reduce orifice diameter to ca. $50 \mu \mathrm{m}$.

5. Obtain an appropriate surface finish.

6. Obtain an adherent coating.

7. Ensure that critical area(s) of the nozzle interior can be masked off. With these steps taken, the spray properties of the coated nozzles can be evaluated, and engine tests of their propensity for deposit formation can also be performed.

\section{Assessment of Various Deposition Methods}

The first step does not require any experimental work. Deposition methods can be ranked under the following criteria: cost, suitability (i.e., whether it can be used to uniformly and reliably coat the interior diameter of a small, high-aspect-ratio hole), environmental impact, and coating adhesion. Possible methods include chemical vapor deposition (CVD) across a range of pressures, physical vapor deposition (PVD), thermal spray, electroplating, and electroless plating.

CVD: A coating method in which vapor-phase precursor species undergo decomposition reactions at the surface to be coated, forming a solid phase on the surface. It can be performed across a wide range of pressures, from high vacuum to atmospheric pressure and higher. Decomposition is not energetically favored at room temperature. It is thus necessary to provide energy to the system to drive the decomposition reactions, either by heating the surface to be coated or by generating a plasma in the precursor gas (plasmaenhanced CVD, or PECVD). CVD is widely used in the semiconductor industry, and PECVD is the method of choice for depositing diamondlike carbon coatings for wear applications. CVD coatings are generally quite smooth, and a great many materials can be deposited by CVD techniques. Thus, it should be possible to deposit materials less prone to coking. CVD hard coatings can be made to adhere well enough for high-stress cutting tools. However, mass production of coated nozzles using vacuum CVD is not likely to be economically feasible, because of the expense of the vacuum equipment. In addition, deposition rates are likely to be slow, and increases in cycle time are generally associated with increased expense. Coating uniformity may also be an issue. Deposition rate is a function of precursor concentration in the volume directly over the area being coated. Thus, to obtain good deposit uniformity, the precursor gas would have to be 
circulating rapidly enough to maintain constant concentration in the orifice at all times. In addition, many of the precursor materials are highly toxic and require stringent safeguards to handle safely. In total, CVD looks borderline feasible for this application and will be examined further only if no other methods can be found.

PVD: Coating methods in which a vapor of atomic clusters having the same composition as the desired coating is derived from a solid (or, more rarely, liquid) source under high vacuum. The vapor then condenses onto the substrate to be coated. Although vapor can be produced in a number of ways (heating the source, sputtering from the source by a plasma, ablating the source with a laser, etc.), virtually all PVD techniques can produce adherent coatings from a wide variety of materials. Unless the desired coating material is itself toxic, the environmental impact of PVD processing beyond its high use of energy is small. However, virtually all PVD techniques are also line-of-sight; that is, the bulk of the vapor moves in straight lines from the source. This situation makes the uniform coating of internal surfaces extremely difficult, particularly at the size scale necessary here. In total, PVD techniques are not satisfactory for coating nozzles.

Thermal spray: Coating method in which a solid material of the same composition as the desired coating (generally in the form of a powder, wire, or rod) is fed into a heat source (plasma arc, electric arc, or flame), melted into droplets, and sprayed onto a substrate. Like PVD and CVD, thermal spray can be used to deposit a wide variety of materials as adherent coatings. Since it can be done in open air, the expense of vacuum equipment is avoided. It is less energy-intensive than PVD, and the only toxicity hazard is if the coating material is toxic. However, like PVD it is a line-of-sight process, and is likewise not satisfactory for coating nozzles.

Electroplating: Coating method in which a solid material of the same overall composition as the desired coating is placed into a conductive bath composed of a solution containing ions of the same material as the solid, together with the substrate to be coated. The solid and the substrate are then placed in an electrical circuit with each other and charged such that the solid undergoes anodic dissolution (i.e., it is oxidized and dissolves), and the electron(s) resulting from the oxidation travel across the circuit to the substrate. There, the ions undergo cathodic condensation (i.e., they are reduced and precipitate) as the electrons from the anodic reaction combine with them. This is generally an open-air process, and the solution is generally aqueous. Electroplating can be used to deposit highly adherent coatings. It is a mature and widely used technology for the large-scale commercial deposition of nickel, chromium, copper, silver, and gold, among other metals. This method has several drawbacks. First, the solutions used are generally toxic, although some materials are less so than others, and electroplating is sufficiently widely used that waste treatment techniques are available. Second, coatings and substrates must be electrically conductive. Third, deposition rate scales with electric field intensity on the substrate. In the case of substrates with simple shapes, this is not a concern. However, the electric field geometry on the inside of the orifices to be coated will likely result in nonuniform deposition rates. In total, electroplating is probably not an appropriate technique for nozzle coating. 
Electroless plating: Coating method in which a substrate is immersed in a solution of ions of the material to be deposited, together with a reducing agent. The most common reducing agents used are sodium hypophosphite, dimethylamine borane, and sodium borohydride. Reduction of the ions takes place in a surface-catalyzed reaction, resulting in the coating deposition. Since the coated surface then acts to catalyze the deposition of the next layer of material, this method is sometime referred to as "autocatalytic plating". Electroless coatings generally contain up to $15 \mathrm{wt} \%$ of a second element from the reducing agent, either phosphorus or boron. The material most widely deposited using electroless plating is nickel, although a wide range of other metals, including copper, cobalt, and tin, can be deposited electrolessly. It is a mature, commercialized coating technique in a wide variety of areas, so cost should not be an issue. With appropriate surface preparation, adhesion can be excellent. As long as the plating solution has reasonably good circulation, electroless plating can be used to uniformly coat complex shapes and internal surfaces, and the deposition rate is on the order of tens of $\mu \mathrm{m} / \mathrm{hour}$. As with electroplating, the plating baths are generally toxic but treatable. In total, electroless plating is the most attractive choice.

The mechanistic details of the electroless plating reactions are complex and in dispute. ${ }^{5}$ However, the overall reactions are well-established. For example, electroless nickel plating using sodium hypophosphite as the reducing agent proceeds via the overall reduction/oxidation reaction

$$
\mathrm{Ni}^{2+}+4 \mathrm{H}_{2} \mathrm{PO}_{2}^{-}+\mathrm{H}_{2} \mathrm{O} \rightarrow \mathrm{Ni}^{0} \downarrow+3 \mathrm{H}_{2} \mathrm{PO}_{3}^{-}+\mathrm{H}^{+}+\mathrm{P} \downarrow+3 / 2 \mathrm{H}_{2} \uparrow
$$

That is, $\mathrm{Ni}$ and $\mathrm{P}$ codeposit, although the actual Ni:P mole ratio is much greater than 1 because of the side reaction

$$
\mathrm{Ni}^{2+}+2 \mathrm{H}_{2} \mathrm{O}+2 \mathrm{H}_{2} \mathrm{PO}_{2}^{-} \rightarrow \mathrm{Ni}^{0} \downarrow+2 \mathrm{H}_{2} \mathrm{PO}_{3}^{-}+2 \mathrm{H}^{+}+\mathrm{H}_{2} \uparrow
$$

As may be seen from both reactions, hydrogen gas is evolved during the deposition process. Over the course of the deposition $\mathrm{pH}$ goes down; depending on the bath composition, this may or may not affect the plating quality. For this reason, most baths contain buffers to stabilize $\mathrm{pH}$.

\section{Experimental Methods and Initial Results Benchtop Nozzle Coating}

To determine the feasibility of electroless nickel (EN) plating for reducing injector orifice diameter, a series of benchtop tests was undertaken. Six-hole valve-covered-orifice (VCO)-type injector nozzles (Fig. 2) with initial orifice diameters $\sim 200 \mu \mathrm{m}$ were obtained from Siemens USA. The nozzle material was carburized $18 \mathrm{CrNi} 8$ steel. Figure 3 shows the internal and external ends of an orifice in its unplated state. A commercial EN plating solution (Caswell, Inc.) was selected for the initial trials.

Before any coating trials were performed, the injector nozzles were degreased with xylene, cleaned with acetone, then air-dried. Initial trial details are summarized in Table 1. After plating, the nozzles were sectioned in different ways and characterized 
metallographically. A borescope (Hawkeye, Gradient Lens Corporation) was also used to examine the interior of the nozzles before and after plating. To measure coating thickness throughout the length of the orifices, sectioned nozzle tips were mounted in epoxy and slowly ground away. When the outer end of the orifice was exposed, the thickness of the sample mount was measured with a Starrett digital micrometer, and a micrograph of the exposed end was taken. Several tens of $\mu \mathrm{m}$ were then polished off of the mount, and the measurement and photographic process were repeated. This process continued until the orifice had been completely ground away (Fig. 4). In this manner, orifice diameter could be determined as a function of position.

The initial results were encouraging but not satisfactory. When the nozzles were on their sides or tip down, nonuniform deposition took place in the orifices. When the nozzles were pointing tip up, reasonably uniform (Fig. 5) deposition took place in the orifice interiors; however, adhesion was poor on the interior (Fig. 6). The borescope indicated that the steel in the tip region had oxidized. These features arose in the following manner from the production of hydrogen gas during the deposition process.

If the nozzles are oriented tip up, hydrogen bubbles agitate the bath and force fresh bath through the orifices as they escape from the nozzle interior. However, because the orifices are below the top of the nozzle interior (Fig. 7), water-vapor-saturated hydrogen accumulates there, slowing or preventing plating and oxidizing the steel. When nickel does plate there, it sits on a loose layer of surface oxide and cannot adhere to the substrate.

Conversely, if the nozzles are oriented tip down or are on their sides, no forced circulation occurs through the orifices, as there are other routes the hydrogen bubbles can take to escape. In the absence of circulation, the bath can be rapidly depleted in some regions of the orifices. The depletion rate can be estimated from the deposition rate and the nickel concentration in the bath. The measured deposition rate in a $200-\mu \mathrm{m}$-diameter orifice that is $1 \mathrm{~mm}$ long was $\sim 10-15 \mu \mathrm{m} /$ hour. Neglecting the presence of phosphorus, this translates to an average mole deposition rate of $3 \cdot 10^{-10} \mathrm{~mol} \cdot \mathrm{sec}^{-1}$ over the internal area of the orifice. The commercial plating bath contains $0.2 \mathrm{M}$ nickel, so the orifice interior initially contains $\sim 6 \cdot 10^{-9} \mathrm{~mol} \mathrm{Ni}$ in solution. That nickel would be removed from solution by deposition in less than half a minute unless replenished by circulating fresh solution through the orifices. Thus, even slight reductions in circulation in the orifices can create concentration gradients in the bath, leading to nonuniform deposition rates.

The initial test results strongly indicated that uniform deposition would require moving the nozzles, agititating the plating bath, and/or forcing the plating bath through the nozzles during the deposition. Several methods were tried, starting with the use of a small peristaltic pump (Fisher Scientific) to force plating bath through the nozzle during the plating process. Ultrasonic agitation (Branson) and rotation of the samples were attempted as well, as were combinations of these methods.

The peristaltic pump eliminated oxidation inside the nozzle body. It also gave better deposition rates inside the orifices than the initial trials (Fig. 8), but it proved to be 
impossible to sustain a flow through an orifice once the diameter had been reduced to ca. $100 \mu \mathrm{m}$. In addition, borescope examination of the nozzle interior showed masses of very fine metallic threads, likely the result of particles in the bath being trapped there and plating together. This problem might be avoided by filtering the bath, but the small pump was unable to sustain any flow at all through a filter of the requisite mesh. Kuczma ${ }^{6}$ claims that commercial-scale plating baths should be filtered continuously by a $1 \mu \mathrm{m}$ or less mesh filter, with at least ten turnovers per hour.

Ultrasonic agitation was tried with nozzles pointing up, pointing down, and on their sides. A few nozzles were also plated with a combination of ultrasonic agitation and peristaltic pumping. By itself, ultrasonic agitation gave poor deposition rates and surface finish (see below). Adding agitation to pumping did not give diameter reductions greater than those achievable by pumping alone.

However, by magnetically rotating the nozzle during deposition —in effect, using the nozzle as a stir bar in a magnetic stirrer - a final orifice diameter of $50 \mu \mathrm{m}$ or less was achieved (Fig. 9). The deposition rate was ca. $25 \mu \mathrm{m} /$ hour, over twice the rate observed in the first bench trials.

With this success, the focus of effort changed to scaling up the coating process, coating multiple nozzles at a time. For this a 20 -gallon plating system was designed and built inhouse, consisting of a large plating tank, a two-stage filtration system containing activated charcoal and synthetic filters, heaters, a pump, and a manifold capable of holding up to 18 nozzles. The manifold would be immersed in the plating bath, and solution would be drawn up from the bath, filtered, and then pumped through the manifold. Initial tests showed that a surge suppressor was needed to prevent air hammer in the lines, and one was installed.

The multiple injector plating tests did not work well, however. The deposition rate inside the orifices was considerably less than that on the nozzle exterior (Fig. 10). The reasons for this are not clear at the time.

At this point, the scaleup effort was tabled, and the main focus shifted to making a few samples for spray visualization testing. For that, the coating adhesion needed to be improved. Since EN plating is widely used, a great deal of information is available on treatments for improving adhesion, both surface and post-plating treatments.

\section{Adhesion Testing}

Weil and Parker ${ }^{7}$ note that some of the hydrogen produced during the plating process can diffuse into a steel substrate. If not removed, the hydrogen can damage the near-surface region of the substrate, reducing adhesion by creating a brittle underlayer. Baking the plated piece at $200^{\circ} \mathrm{C}$ for several hours immediately after plating allows the hydrogen to diffuse out of the part before it can cause damage. This process frequently improves adhesion. 
All of the available surface preparation techniques contain two basic parts: i.e., removing surface contamination and rendering the surface chemically active in a way that promotes bonding between the surface and the plating. For example, one surface preparation method for low-carbon steel is as follows ${ }^{8}$ :

1. High alkalinity $(\sim 6 \mathrm{M} \mathrm{NaOH}+$ buffers $)$ soak clean at $170-190^{\circ} \mathrm{F}\left(77-88^{\circ} \mathrm{C}\right)$ for 5 $\min$

2. Rinse

3. Alkaline electroclean $(\sim 1.2 \mathrm{M} \mathrm{NaOH}+$ buffers) (anodic or periodic reverse ending anodic) at $150-180^{\circ} \mathrm{F}\left(66-82^{\circ} \mathrm{C}\right)$ and $20-100 \mathrm{~A} / \mathrm{ft}^{2}\left(220-1100 \mathrm{~A} / \mathrm{m}^{2}\right)$ for 2 $\min$

4. Rinse

5. Rinse

6. $50 \mathrm{vol} \% \mathrm{HCl}, 10 \mathrm{vol} \% \mathrm{H}_{2} \mathrm{SO}_{4}$ or acid salts for $1 \mathrm{~min}$

7. Rinse

8. Rinse

9. $0.25-0.5 \mathrm{vol} \%$ ammonium hydroxide electroless nickel predip for $30 \mathrm{sec}$

10. Electroless nickel plate

The initial alkaline cleaning steps are to remove surface oxides and a small amount of metal, the acid exposure is to activate the surface such that the deposition process starts quickly, and the final ammonium hydroxide dip is to neutralize any remaining acid on the surface. ${ }^{9}$ This last step can be skipped if rinsing is thorough, and should be skipped if the plating bath contains no ammonia.

Tests were performed on polished $\mathrm{H}-13$ tool steel flats plated using the commercial bath. Coating adhesion was determined by indenting the coated surface in a Rockwell $\mathrm{C}$ test, then examining the indentation for loss of coating. Highly adherent coatings do not delaminate or separate from the substrate, while coatings with poor adhesion delaminate extensively around the circumference of the indentation (Fig. 11).

Post-treatment adhesion was uniformly quite poor. It was suggested that a phosphoric acid etch could be used in place of the high-alkalinity soak clean. The acid etch appears (Fig. 12) to selectively remove material from the steel surface, preferentially attacking grain boundaries and other stressed areas. This attack roughens the surface on a microscopic scale, improving adhesion by mechanical interlocking between the plate and the substrate. This may not be sufficient to prevent delamination during tests, and the damage to surface finish is also of concern. In addition, the electrocleaning steps would be problematical with the orifice geometry, for the same reason that electroplating was judged to be inappropriate for nozzle coating: i.e., the sharp radii of curvature of the orifice edges would lead to high local electric field strengths, bringing about more rapid removal of material and changes in the orifice exit geometry. A further complication is that the orifice interiors, with their large negative radius of curvature, would have correspondingly weaker local electric field strength, leading to slower removal of material than from the exterior. To obtain information regarding improved surface preparation techniques, inquiries were made with commercial plating companies. 


\section{Hardness Testing}

Following the thickness profile measurement, an injector nozzle coated with $\sim 75 \mu \mathrm{m}$ EN was sectioned so as to expose the outer nozzle body in cross section. A Knoop microhardness tester (Tukon Model 300) was used to take multiple hardness measurements across the plating under a $100 \mathrm{~g}$ load, and Knoop microhardness was then plotted as a function of position.

\section{Surface Finish Measurements}

An optical profilometer (ADE PhaseShift MicroXAM) was used to measure the surface finish $\left(\mathrm{R}_{\mathrm{A}}\right)$ on the orifice interiors. To maximize the area examined, plated and unplated injector nozzles were ground away from the tip end until the orifice interiors were exposed.

As described above, as-machined orifices are quite rough and must be smoothed by hydroforming. It is possible that EN plating could be used to reduce the need for this step, if the coating process reduces $\mathrm{R}_{\mathrm{A}}$ sufficiently. To determine this, an $\mathrm{H}-13$ flat was ground with various grades of $\mathrm{SiC}$ sandpaper (Streuers). Surface finish was measured with an optical profilometer, as above, taking measurements in ten locations and averaging them. The flat was then plated for $45 \mathrm{~min}$. using the commercial bath, and the surface finish was again measured in ten locations using the optical profilometer.

\section{Masking}

As described above, the initial rounds of coating tests used off-the-shelf nozzles. These are adequate for coverage, adhesion, and surface finish tests, but because of the tight clearances between the needle and the needle guide area (Fig.13), neither spray nor engine tests can be performed without preventing EN from depositing onto the needle guide area. That is, if the needle guide area is plated, it will be impossible for the needle to fit into the nozzle. If EN plating comes into widespread use as part of the total injector fabrication process, this should no longer be necessary; needles will be sized to fit the needle guide after plating. For test purposes, though, some means will have to be used to keep the needle guide coating-free.

A commercial masking compound (Masktec, Inc., MT-1024) was obtained for test purposes. An initial test was done by masking an area of a polished $\mathrm{H}-13$ flat according to the manufacturer's directions and plating with the commercial bath in a simple bench setup. Following that, needle guides on a pair of nozzles were masked and plated with the same setup.

\section{Commercial Nozzle Coating}

After the above-described problems with coating adhesion, a commercial EN plating company was consulted. They were able to coat a number of nozzles using pulsed flow forced circulation, avoiding the problems with bath depletion and reduced growth rate under high flow. They produced three batches of coatings, with analysis and feedback in between batches. The coating distribution on some of the nozzles they plated was 
examined in the same manner as the benchtop-coated nozzles described above. Adhesion tests were also performed on the exterior of the coated nozzles.

\section{Final Results and Discussion/Current Status Benchtop Nozzle Coating}

All of the results for the benchtop nozzle coating effort are described above; current efforts are focused on the commercial coatings.

\section{Adhesion Testing}

Anodic alkaline electrocleaning did not work with the H-13 steel samples because the samples were quenched in oil, leading to the presence of near-surface high-carbon regions. Alkaline electrocleaning removes surface oxide and some of the metal, so the cleaned surface was decorated with areas of pure carbon. Any plating deposited there would not adhere to the substrate at all, with the results observed. Thus, alkaline electrocleaning would not have worked for the nozzles in any case; they are deepcarburized, so they also have extensive regions of high carbon concentration. Such materials require periodic reversal electrocleaning, alternating between anodic and cathodic charging of the parts to be coated. ${ }^{9}$

\section{Hardness Testing}

Figure 14 shows Knoop microhardness of plating plotted as a function of distance from the substrate, together with the results of several hardness tests on the substrate material in the near-interface region. To compensate for potential measurement errors with the hardness tester, each indent was measured twice by the computer on the tester, then was photographed and measured twice from the photograph. The data converge reasonably well.

It appears that as the plating process proceeds, the coating grows softer. This softening is likely due to chemistry changes as the bath becomes depleted in nickel and the $\mathrm{pH}$ decreases, leading to an increase in phosphorus concentration. This hypothesis is consistent with the literature regarding mechanical properties of EN plating. ${ }^{7}$ It is not known what EN hardness would be best for this application, but the differences indicate that some degree of tailoring should be possible. Ideally, if the needle seat cannot be kept free of coating, lower hardness and higher ductility would be preferable.

\section{Surface Finish Measurements}

The method of plating has a marked impact on the surface finish of the orifice interior (Fig. 15). In general, EN plating reduces $R_{A}$ and changes surface morphology from erose to rounded (Fig. 16). This effect becomes more pronounced the longer the plating proceeds. However, plating done with ultrasonic agitation is in most cases rougher than the substrate. This roughness likely arises from the inability of ultrasonic agitation to remove hydrogen bubbles from the plated surface. If the bubbles stay in place for too long, they prevent plating under them. This condition leads initially to shallow dimples in the surface, in which bubbles are more easily trapped. The eventual result is a pockmarked surface. Interestingly, however, the combination of ultrasonic agitation and 
forced flow resulted in a slightly smoother surface than forced flow alone for the same plating time, and a much smoother surface than ultrasonic agitation alone.

The surface finish results using roughened $\mathrm{H}-13$ flats corroborate the overall trend seen in the orifice interiors. Although EN plating is highly conformal at a scale significantly greater than the surface roughness, it reduced surface roughness when applied in thicknesses greater than the surface roughness. At all initial surface finishes, EN plating reduced $\mathrm{R}_{\mathrm{A}}$ by between $15 \%$ and $70 \%$ (Fig. 17).

\section{Masking}

The commercial maskant worked well on larger pieces. Obtaining good coverage on the needle guide was quite difficult, however. In practice, this problem would lead to unacceptably high labor costs for nozzle plating. Fortunately, as described above, integrating plating into the fabrication process would allow needle fitting after plating, eliminating the need for masking the guide area.

\section{Commercial Nozzle Coating}

Coating coverage in the orifices was excellent (Fig 18) from the first batch, although surface finish and adhesion were not as good. After the first trial, adhesion was likewise excellent (Fig. 19), with no delamination taking place around the Rockwell indentations. Surface finish was still problematical, however. Apparently, as with ultrasonic agitation in the bench tests, bubbles of hydrogen gas generated during the plating process adhered to the surface, blocking some areas and preventing them from receiving as much plating (Fig. 20). In the third batch, surfactants were added to the bath to prevent bubbles from staying on the surface, and surface finish improved markedly (Fig. 21).

\section{Conclusions and Future Work}

The initial data indicate that electroless plating of fuel injector nozzles to reduce orifice diameter to $50 \mu \mathrm{m}$ is feasible on a commercial scale. With the exception of masking the needle guide on the commercially plated nozzles, the research plan described in the Introduction has been completed.

The commercial coating company has a proprietary technique for chemically removing EN plating without damaging the substrate. They are preparing nozzles for testing by first plating the entire surface, then masking the orifices and removing the nickel from the rest of the surface. Spray and engine testing should be possible with the nozzles so prepared, and arrangements have been made to perform tests once the nozzles are available.

Together with engine performance testing with small-orifice injector nozzles, three other areas should be addressed:

1. Impact fatigue resistance of the coatings over time, particularly in the vicinity of the needle seat (Fig. 22).

2. Cavitation erosion resistance of the coatings, particularly in the orifices themselves. 
3. The ability of the coatings to reduce or eliminate the growth of combustion deposits in the orifices and on the exterior of the nozzle.

The last of these has been under examination in bench tests at ANL and elsewhere. ${ }^{10}$ Examination of the other two will proceed as follows:

To test the impact fatigue resistance of coated nozzles in the needle seat area, a highfrequency reciprocating wear tester will be modified so as to drive a needle into a plated nozzle at $\sim 150 \mathrm{~Hz}$. Unplated nozzles and nozzles with different plating thicknesses will be tested, and the impact damage in the needle seat area will be determined as a function of coating thickness/presence.

Because of the difficulties in rigorously testing cavitation erosion resistance, ${ }^{11}$ initial characterization will be limited to estimates based on plate hardness, followed by ultrasonic mass loss measurements to confirm the results. ${ }^{12}$

The results of these tests may force a change in plating composition or type, depending upon how well the commercial plating holds up. If the plating behaves well, long-term engine tests leading to fleet tests are the likely next step.

\section{Acknowledgments}

This work was supported by the U. S. Department of Energy, Automotive Propulsion Materials Program, under B\&R EE07-01/49879. The authors gratefully acknowledge the assistance of Bert Hobein, Jianmin Chen, Jamie Griffith, Brad Kaspar, Brad Duling, LaNiece Thomas, Robert Straub, and Dan Englebert.

\section{Table}

Table 1: Experimental conditions for initial bench tests

\begin{tabular}{|c|c|c|c|}
\hline Duration (min) & $\begin{array}{c}\text { Bath Temperature } \\
\left({ }^{\circ} \mathrm{C}\right)\end{array}$ & Nozzle Orientation & $\begin{array}{c}\text { Did Orifices } \\
\text { Plate Uniformly? } \\
(\mathrm{Y} / \mathrm{N})\end{array}$ \\
\hline 90 & $87-91$ & Upright (orifices up) & $\mathrm{Y}$ \\
\hline 160 & ca. 95 & Sideways & $\mathrm{N}$ \\
\hline 190 & $82-98$ & $\begin{array}{c}\text { Inverted (orifices } \\
\text { down) }\end{array}$ & $\mathrm{N}$ \\
\hline
\end{tabular}




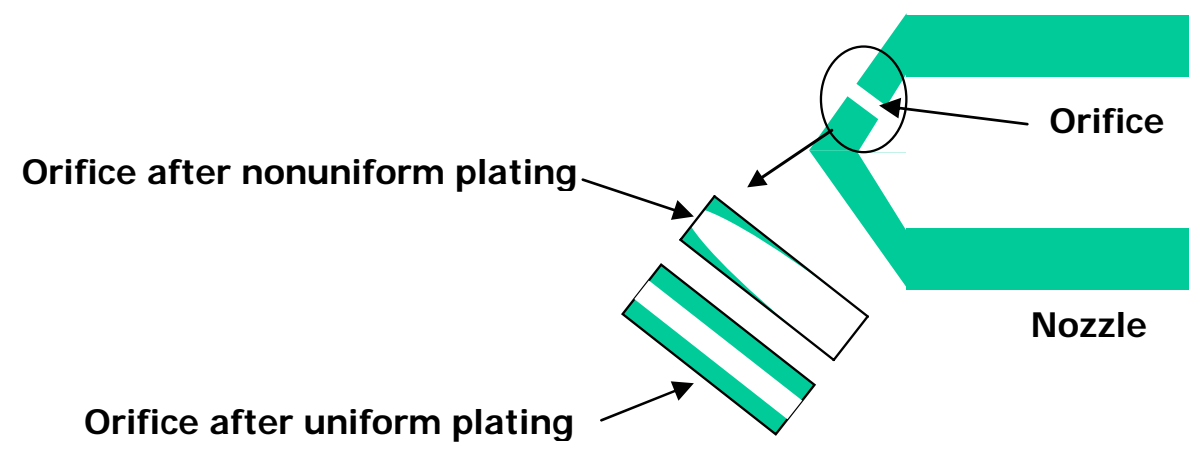

Figure 1: Simplified schematic drawing of concept for orifice diameter reduction. A spray hole in a simple nozzle is reduced in diameter by having coating applied to its interior. This coating can be applied uniformly or in such a way as to produce a tapered hole.

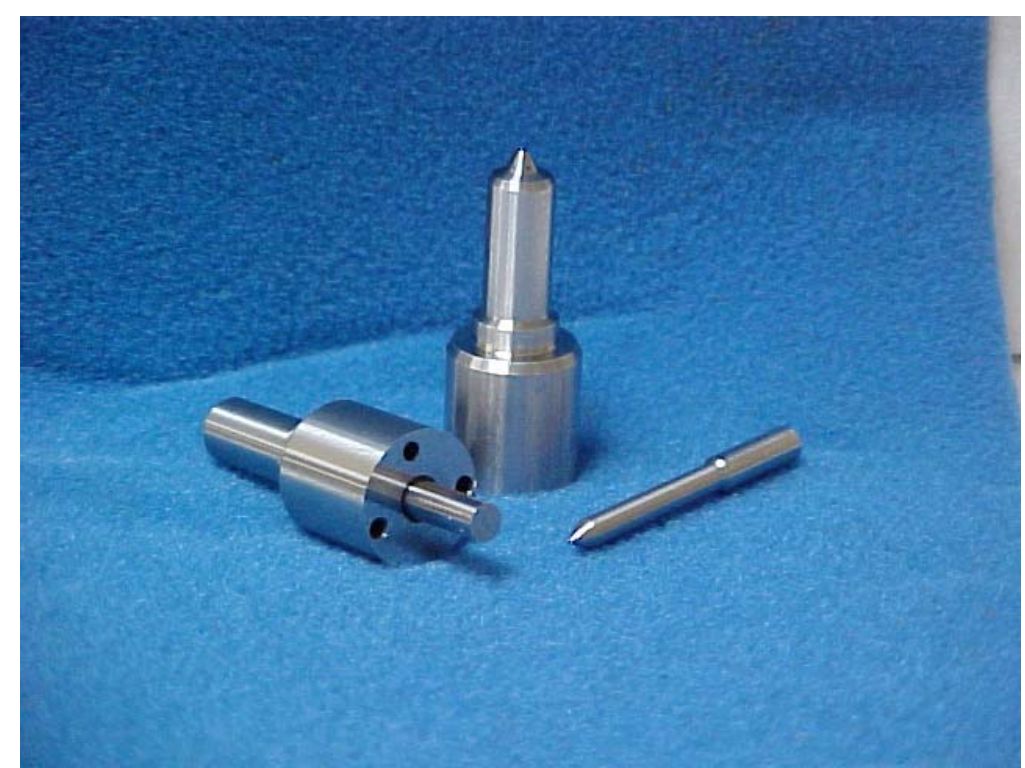

Figure 2: Injector nozzles to be coated. 


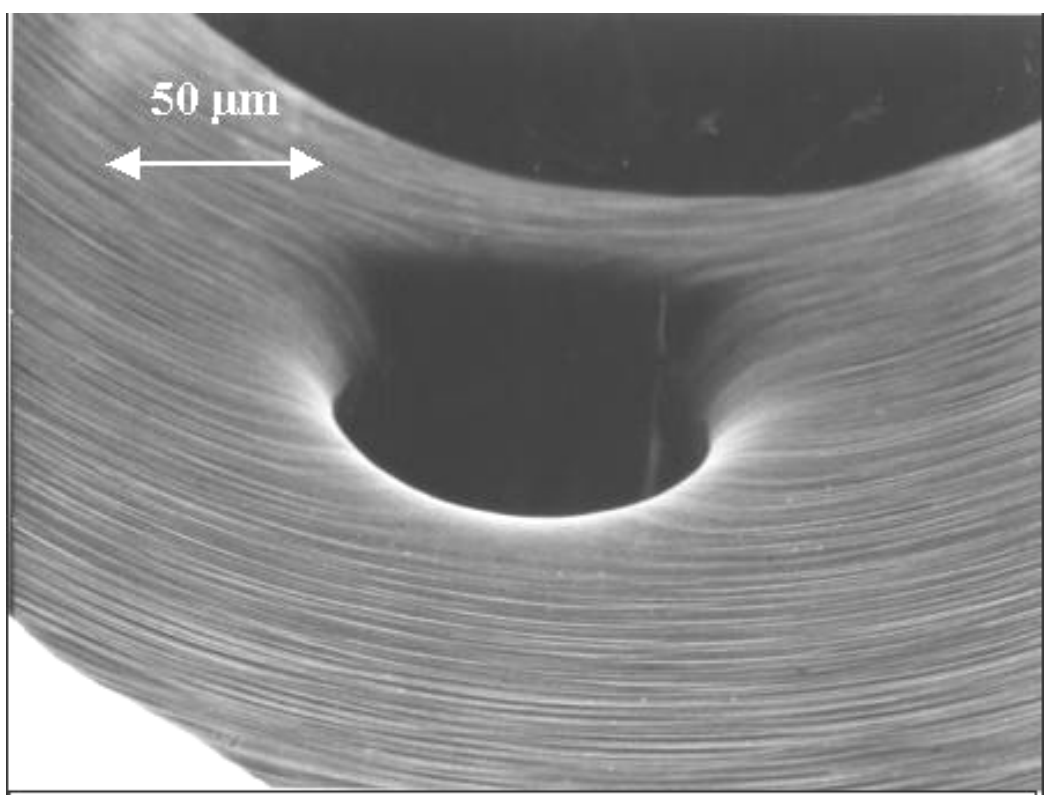

(a)

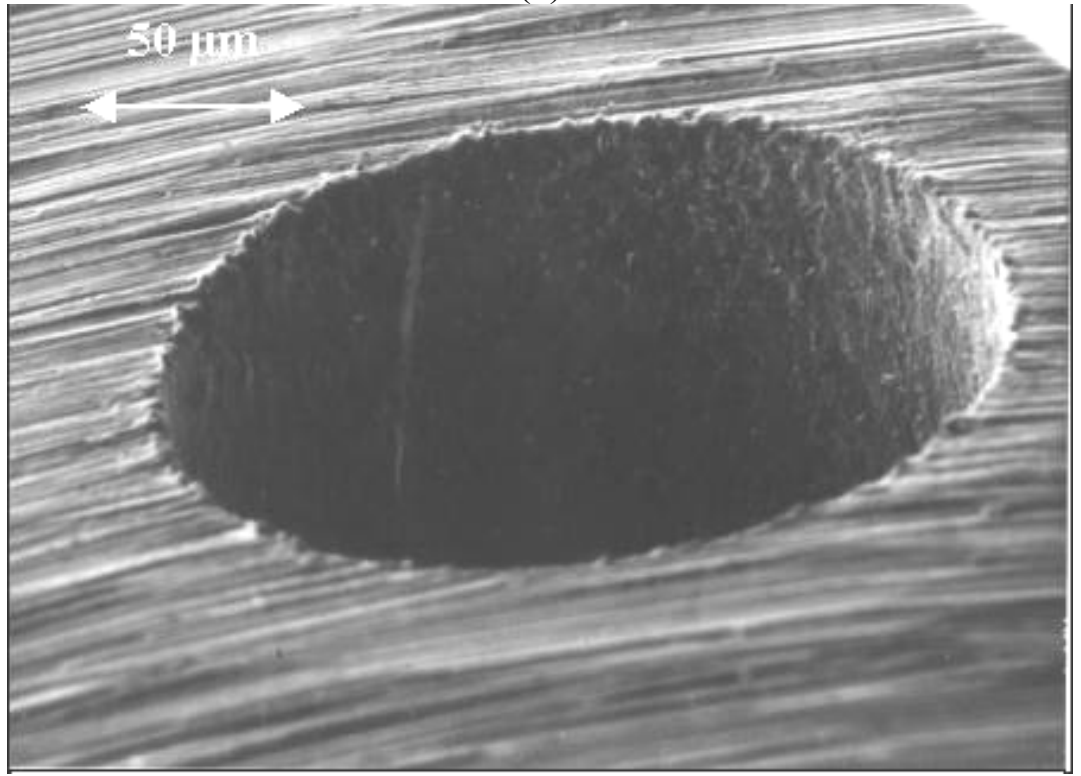

(b)

Figure 3: (a) Internal end of orifice before plating. (b) External end of orifice before plating. 


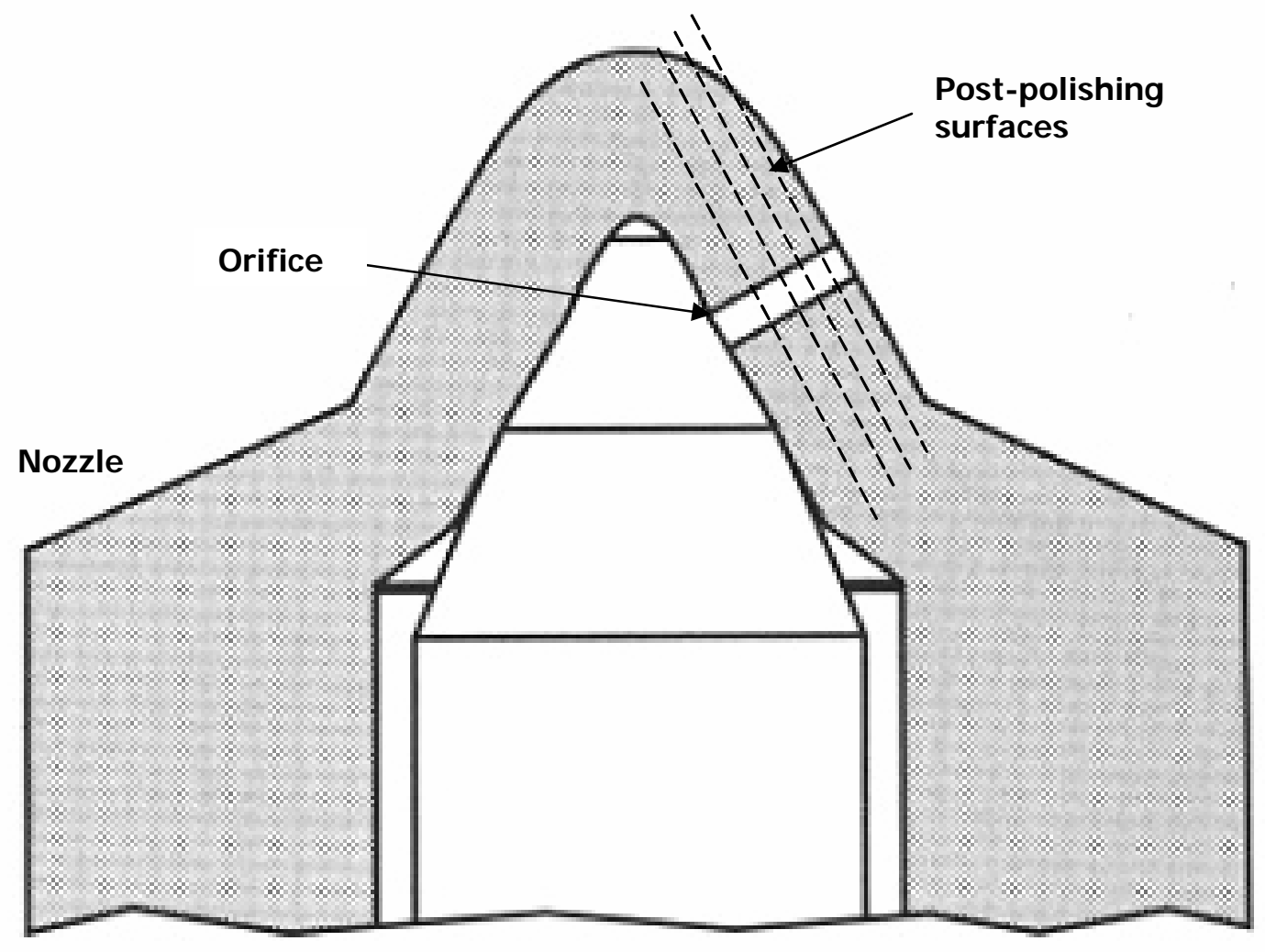

Figure 4: Schematic drawing of orifice diameter measurement for upright tests. Only one orifice is shown. The dotted lines show where the nozzle is to be polished away, exposing successive cross sections of the coated orifice.

Orifice Diameter vs. Position

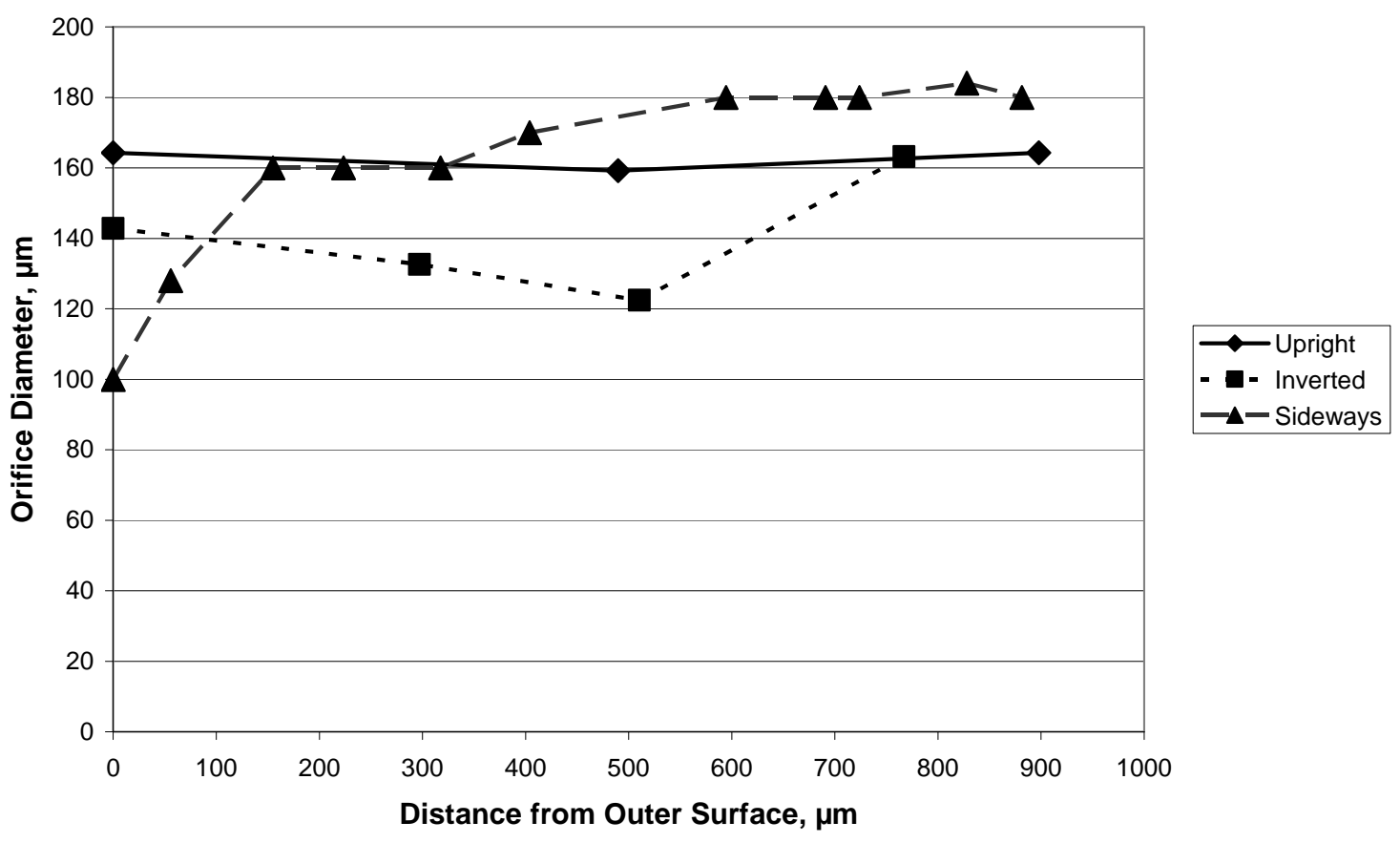


Figure 5: Orifice diameter after plating for initial bench trials.

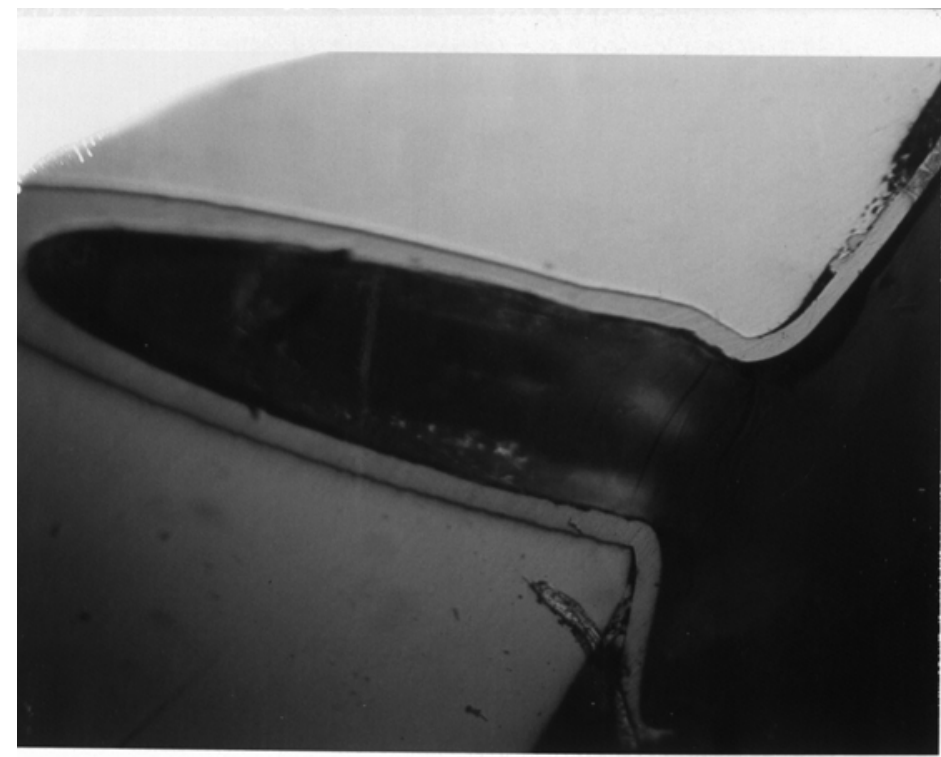

Figure 6: Micrograph of orifice interior end after plating, showing delamination. The image is ca. $800 \mu \mathrm{m}$ wide.

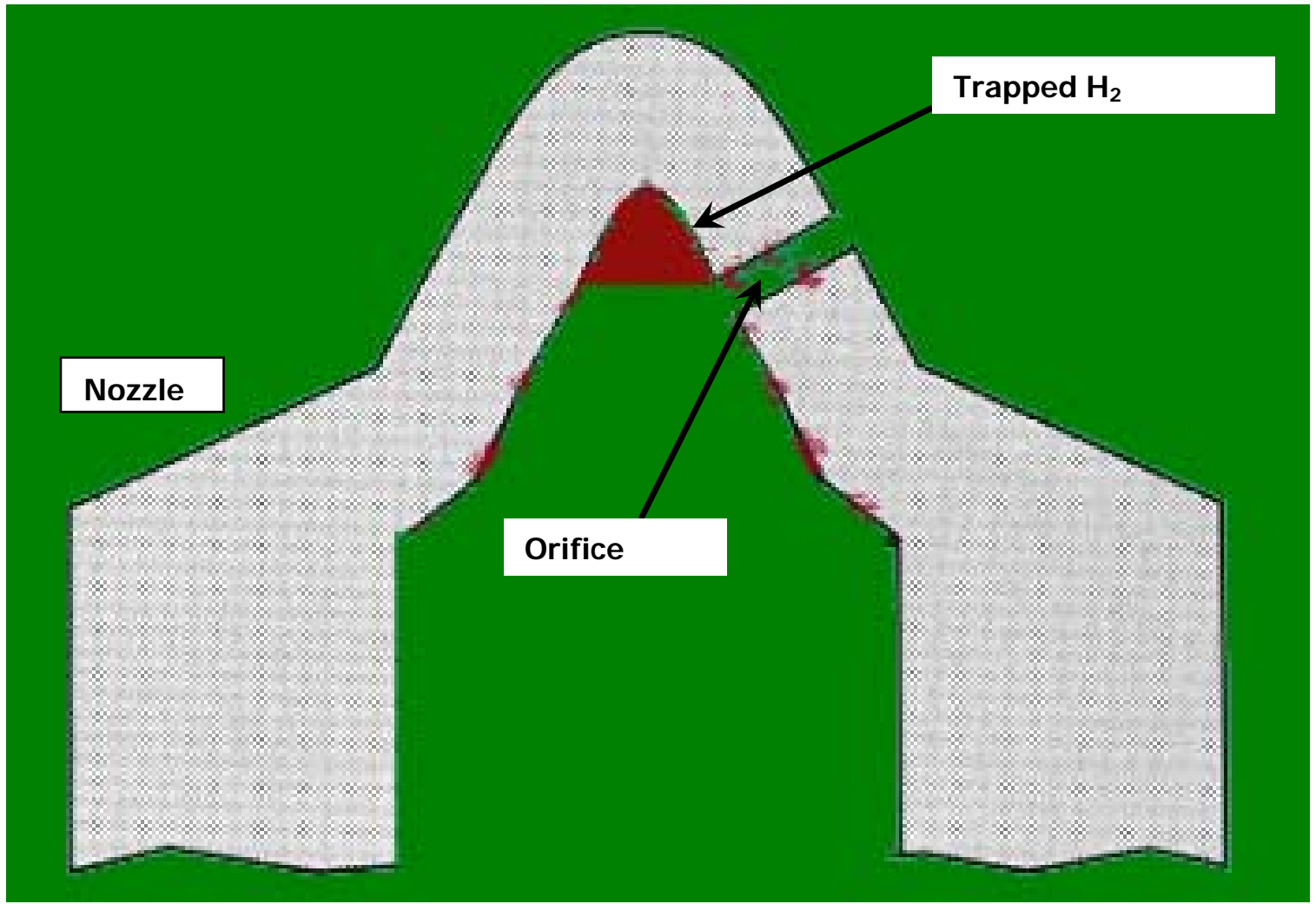

Figure 7: Schematic drawing of nozzle interior during deposition while upright. Again, only one orifice is shown. As hydrogen gas evolves during the plating process, it accumulates above the orifice in the tip. 


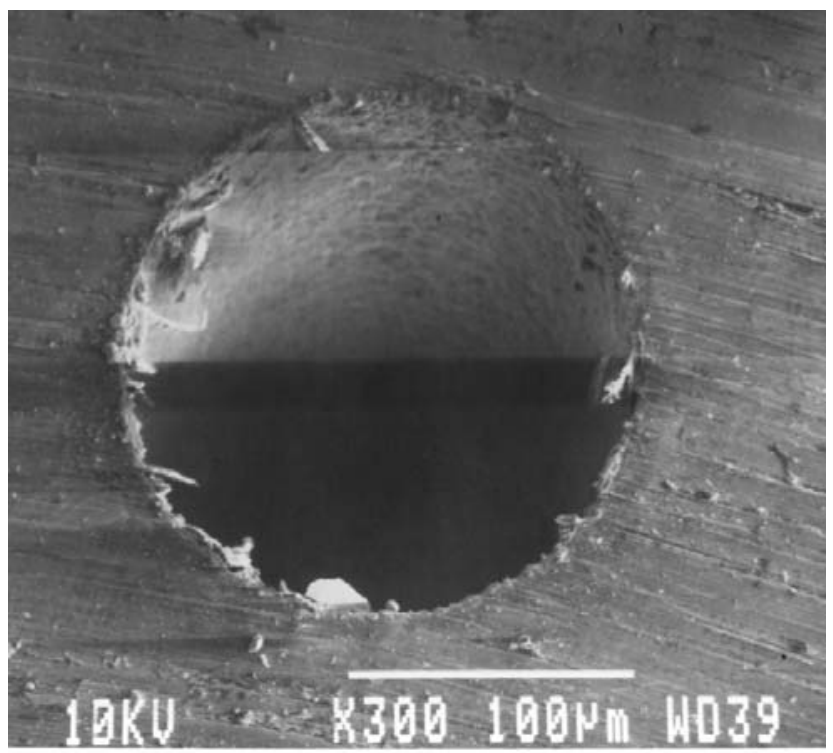

(a)

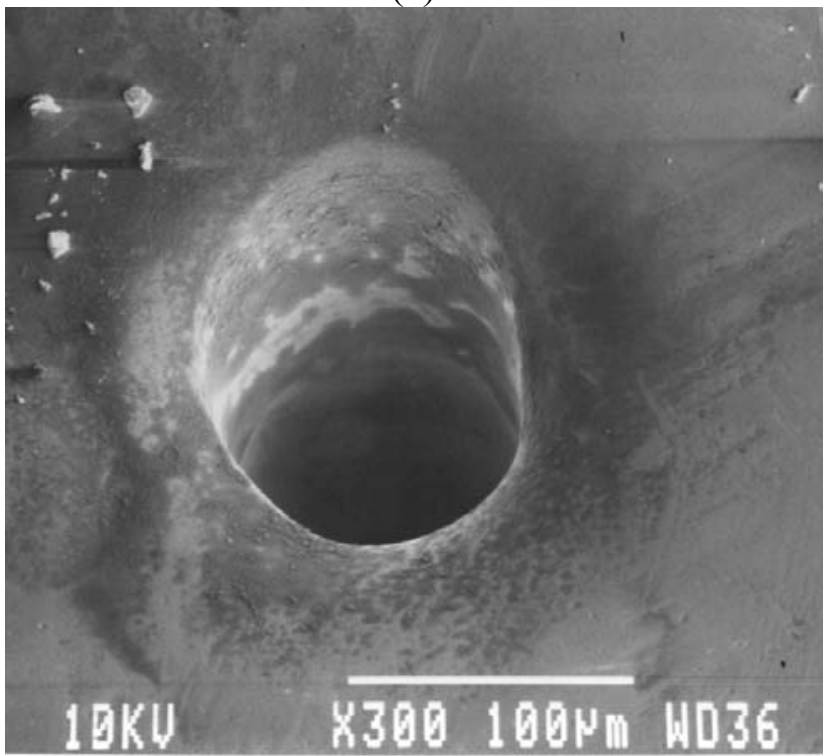

(b)

Figure 8: Scanning electron micrograph of exterior end of orifice before (a) and after (b) plating using forced circulation. 


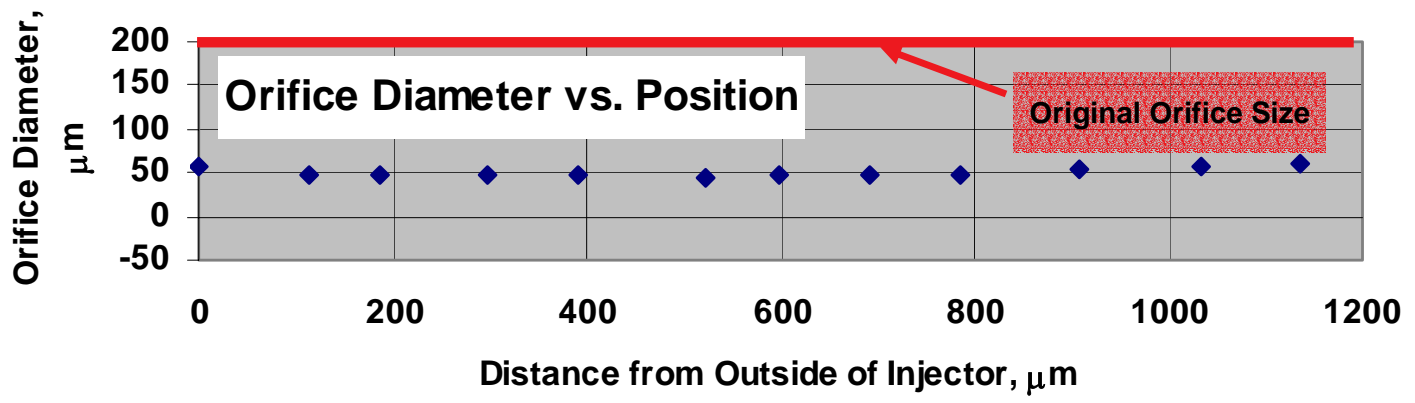

(a)

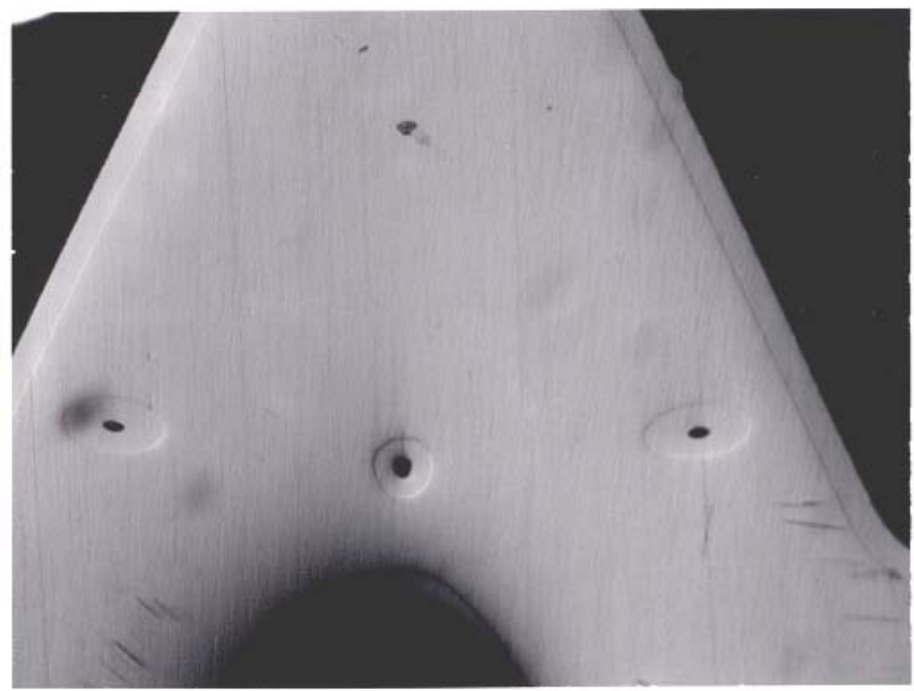

(b)

Figure 9: (a) Orifice diameter after plating via spin. (b) Cross-section of plated nozzle. The original diameter of the orifice in the center was $200 \mu \mathrm{m}$. 


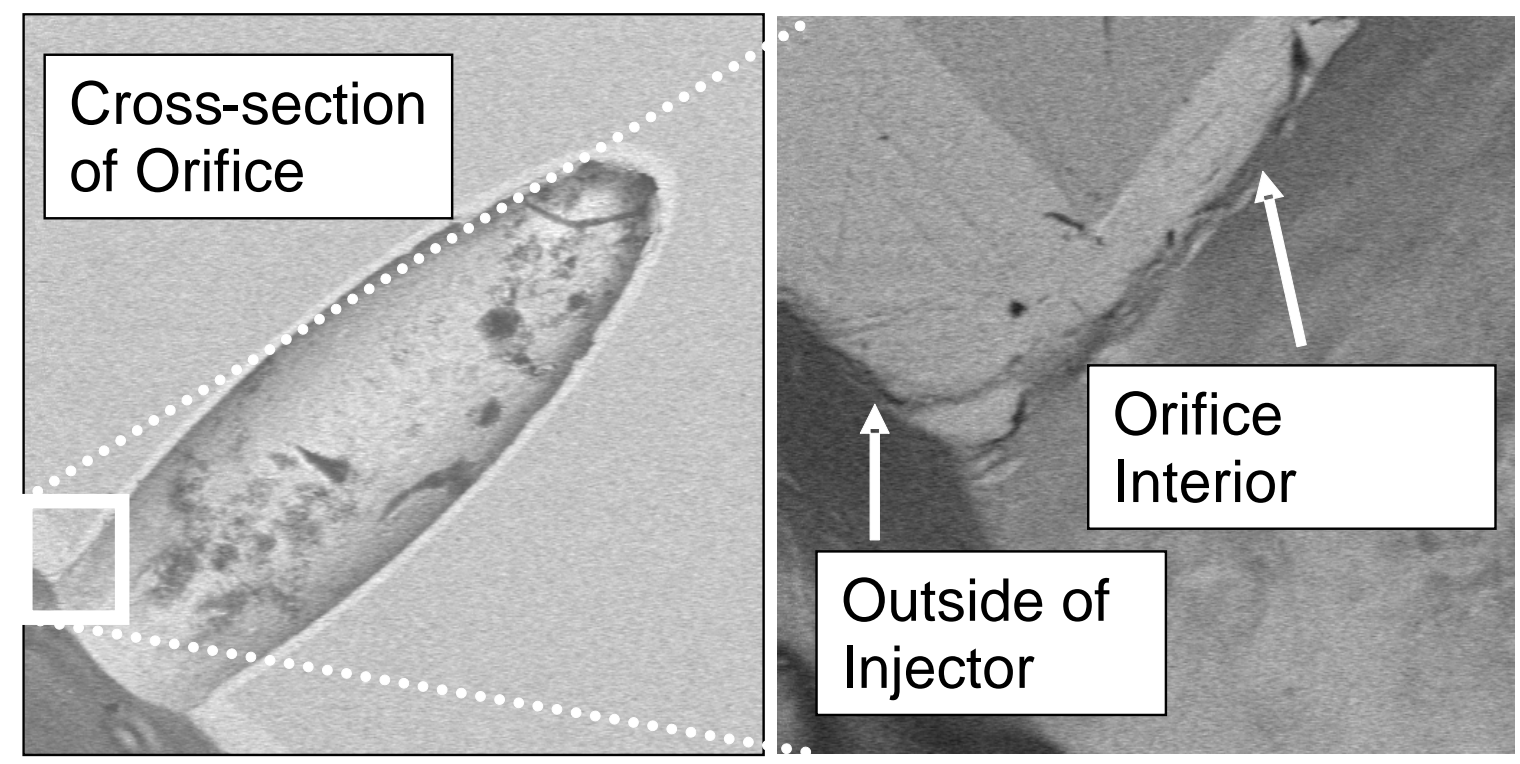

Figure 10: Micrograph of external end of orifice following forced-circulation test with manifold. The lefthand image is $533 \mu \mathrm{m}$ across, and the righthand image is $80 \mu \mathrm{m}$ across.

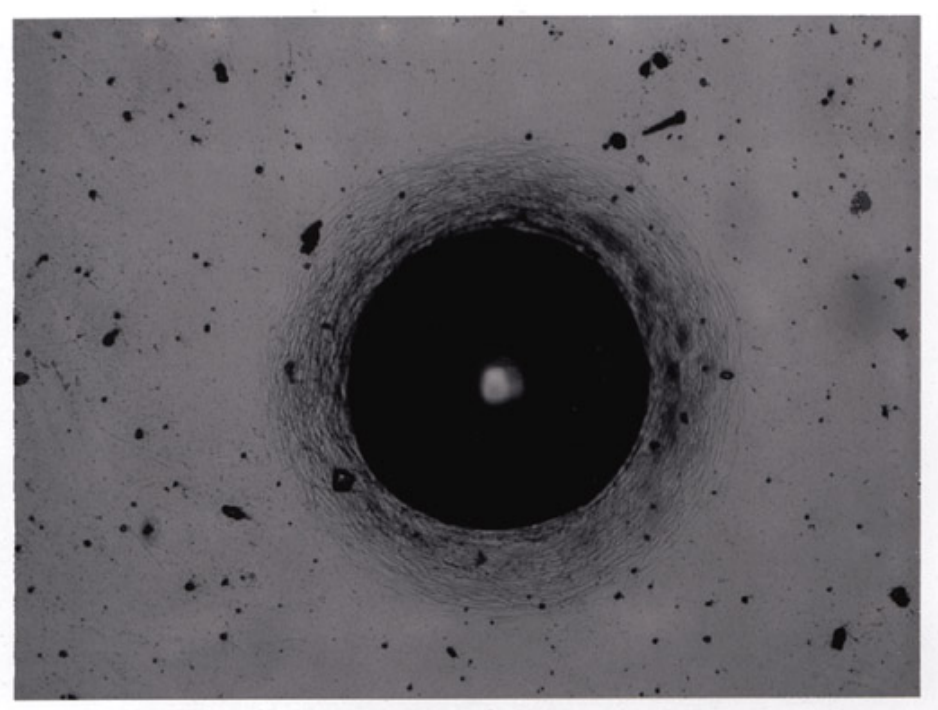

(a) 


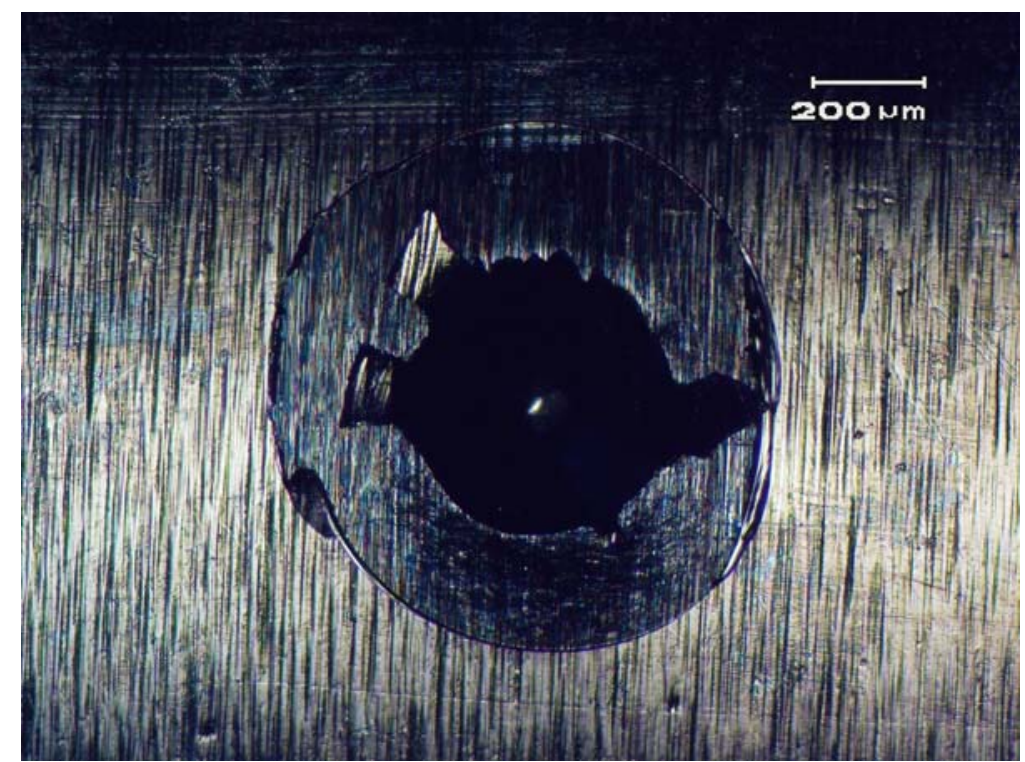

(b)

Figure 11: (a) Adherent coating after Rockwell $\mathrm{C}$ indent adhesion test. (b) Nonadherent coating after Rockwell $\mathrm{C}$ indent adhesion test. The darker area around the central indentation in (b) is where the plating has completely delaminated from the substrate.

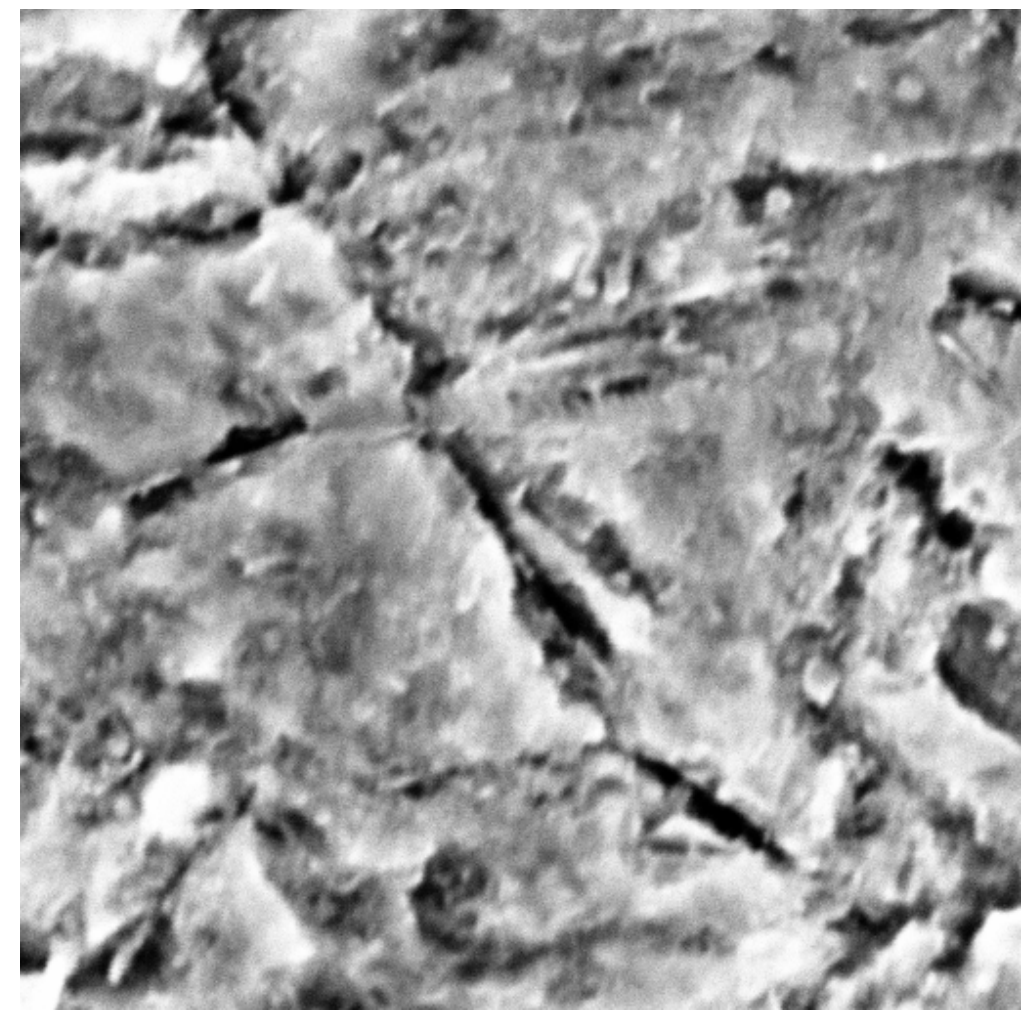

Figure 12: Micrograph of phosphoric acid-etched steel surface. The image is $8.9 \mu \mathrm{m}$ across. 


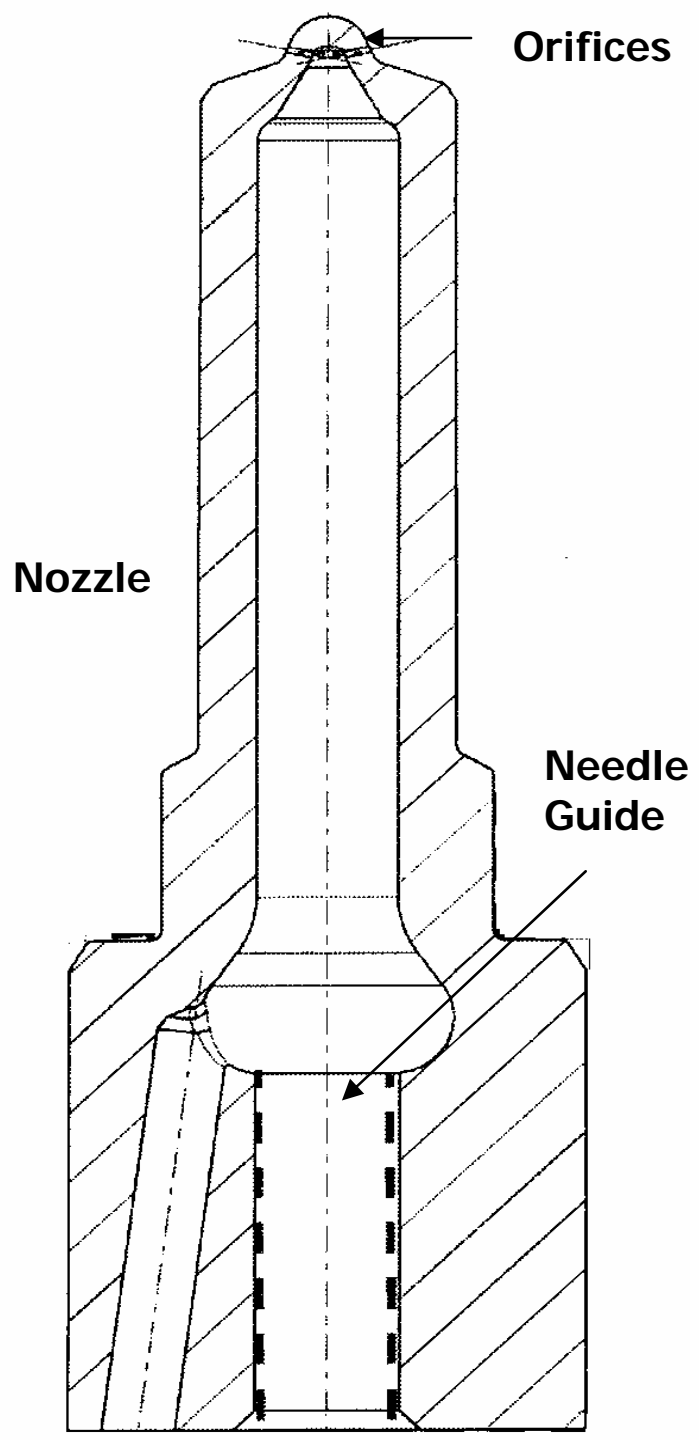

Figure 13: Schematic of nozzle showing needle guide area (highlighted with dotted lines). (Schematic courtesy of Siemens AG.) 


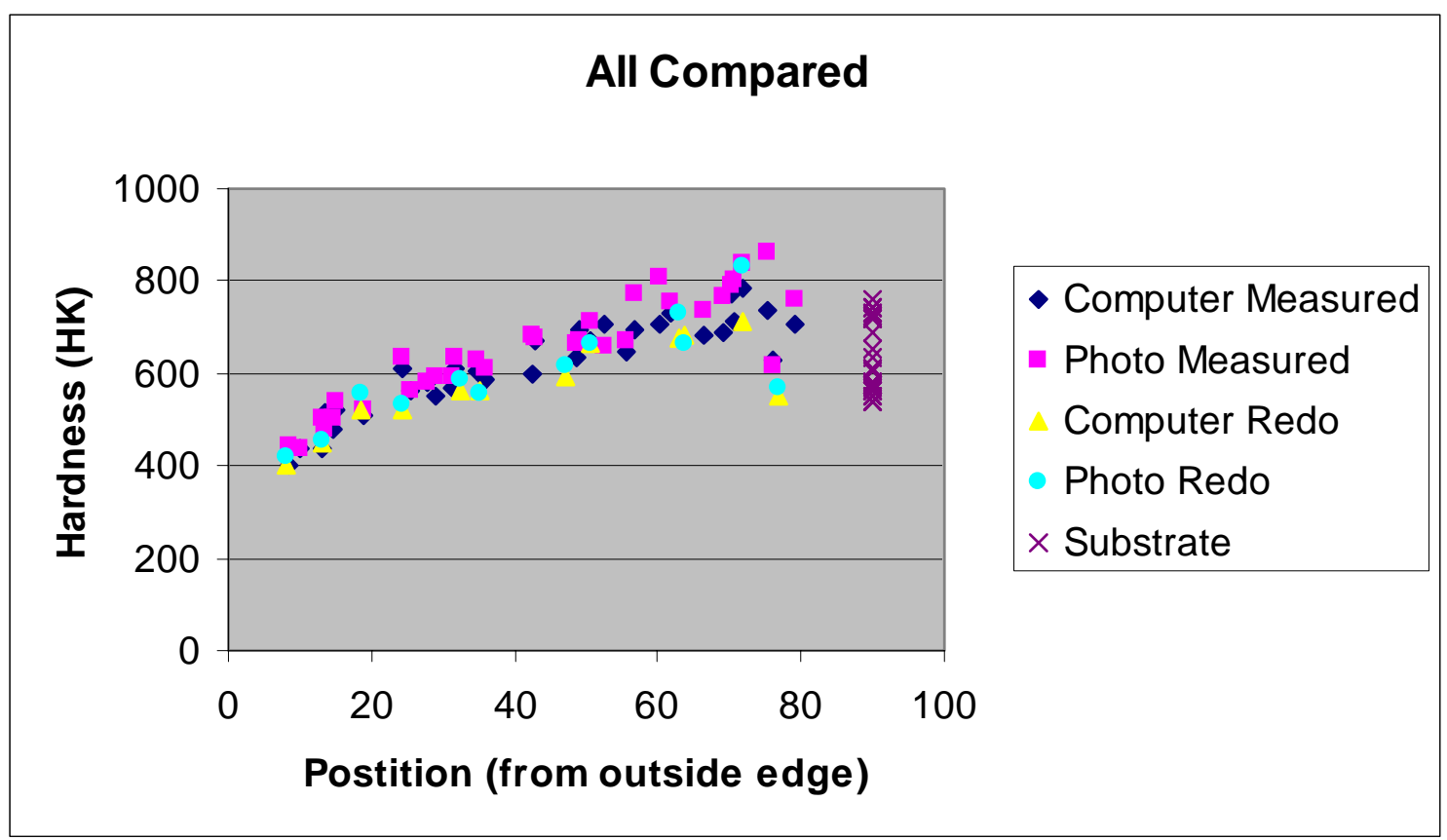

Figure 14: Knoop microhardness of EN plating as a function of distance from the substrate.

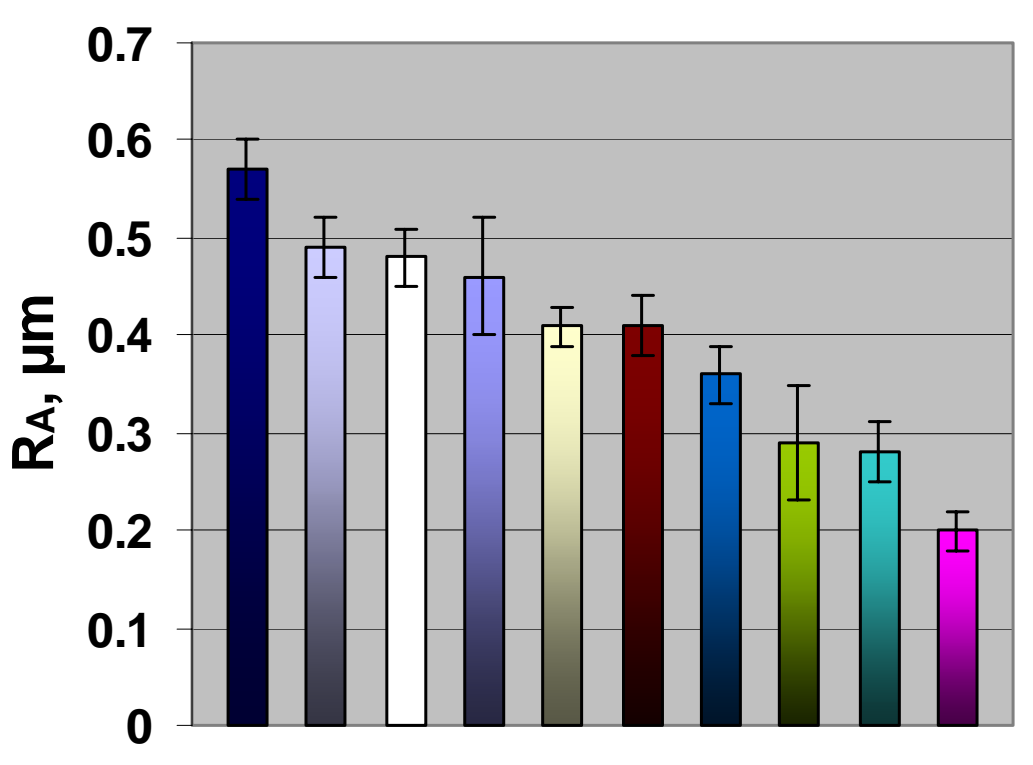

- US UR 30mins

$\square$ US UD 30mins

$\square$ Unplated

US SW 30mins

Magnetic 30mins

- Pull 15 mins

Pull 30 mins

$\square$ Pull 1hr

$\square$ US + Pull 30mins

Magnetic 2hrs

Figure 15: Surface finish as a function of plating conditions. "US" denotes ultrasonic agitation, "Magnetic" denotes magnetic spinning of nozzles in the bath, and "Pull" denotes forced circulation by pulling bath through the nozzles from the exterior tip. "UR" indicates that the nozzle was plated standing upright, "UD" indicates that the nozzle was upside down, and "SW" indicates that the nozzle was sideways. 


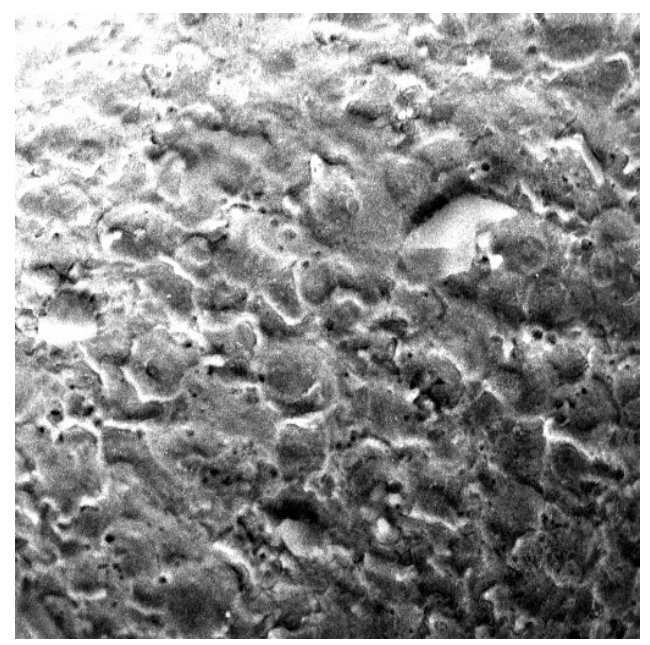

(a)

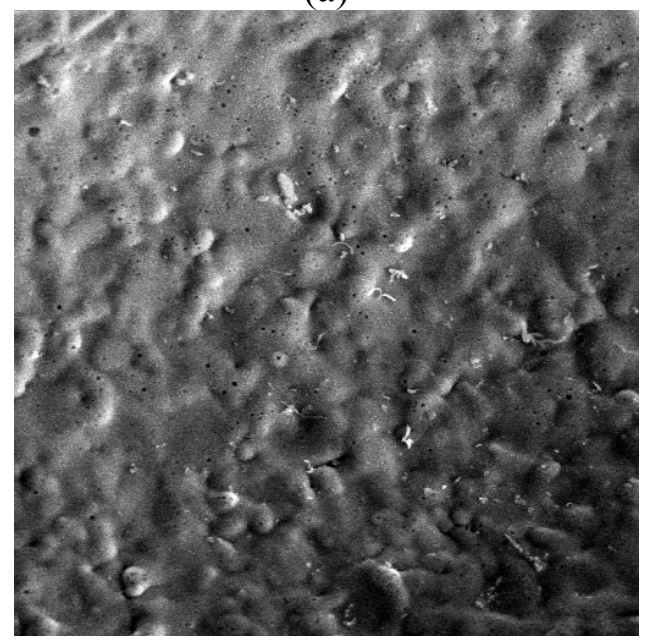

(b)

Figure 16: (a) Micrograph of unplated orifice interior. (b) Micrograph of orifice interior after plating for 15 minutes using forced circulation. Both images are $100 \mu \mathrm{m}$ across. 
Surface Roughness

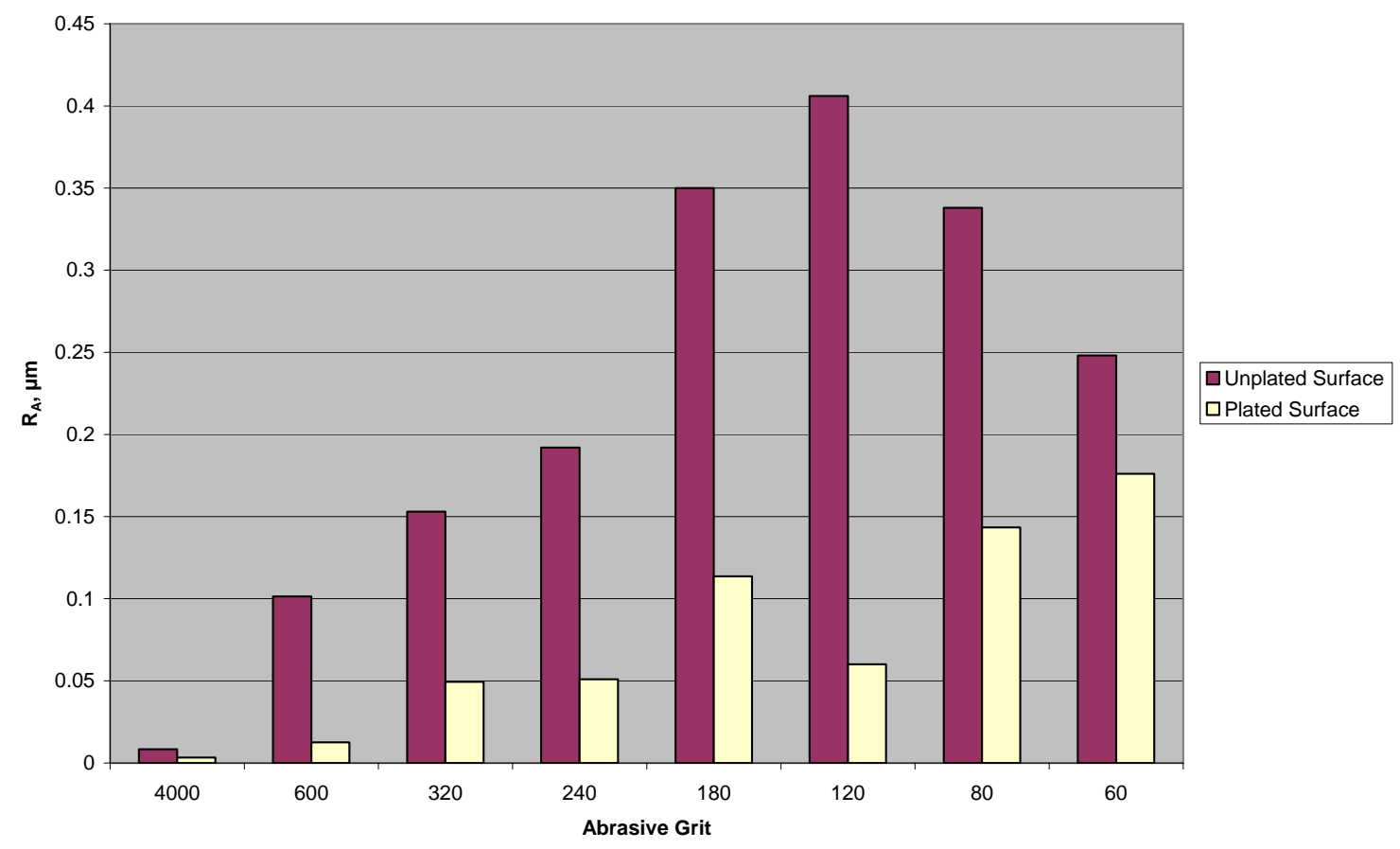

Figure 17: Pre- and post-plating surface roughness.

Orifice Diameter on Commercially-Plated Nozzle \#1

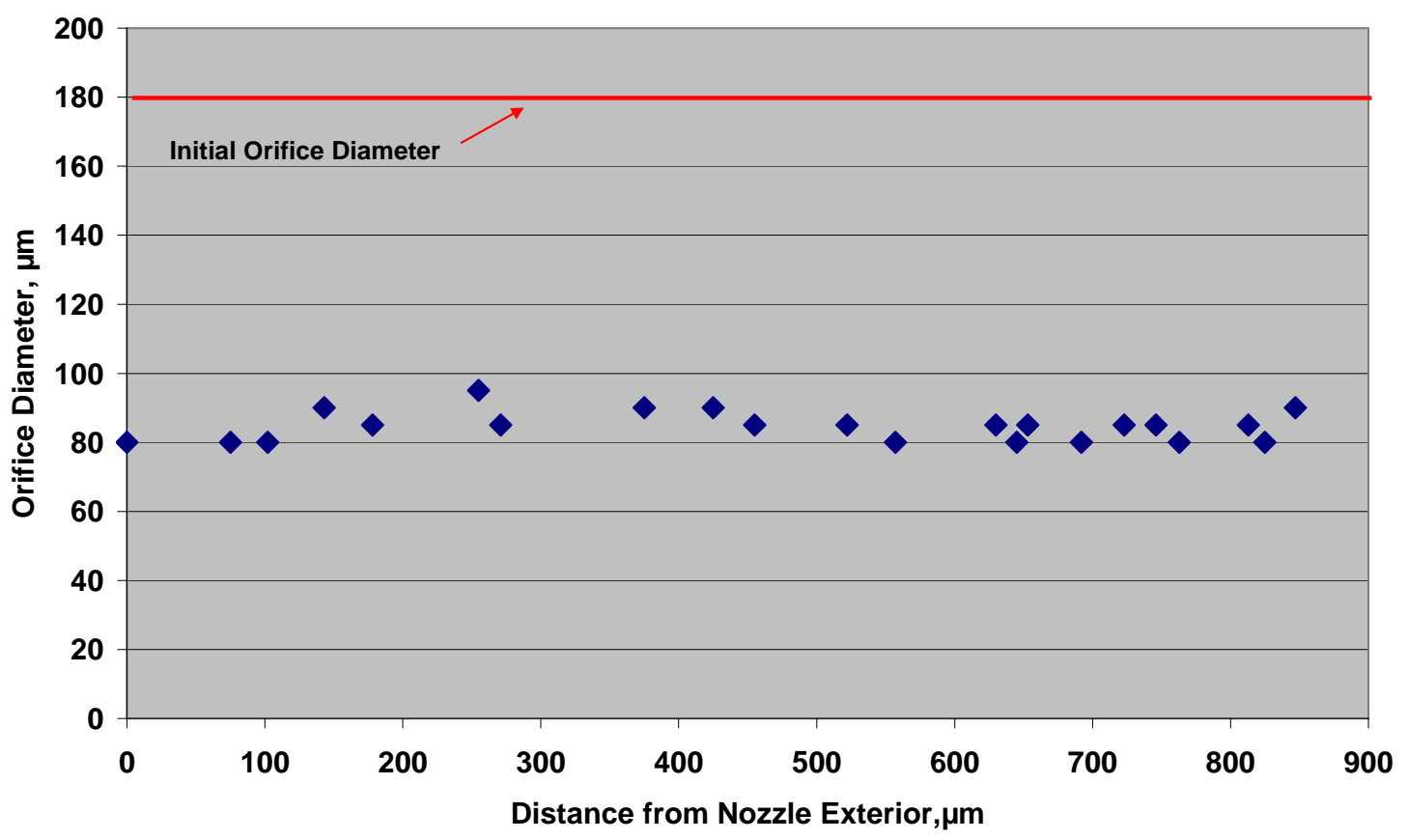

Figure 18: Orifice diameter after commercial plating. 


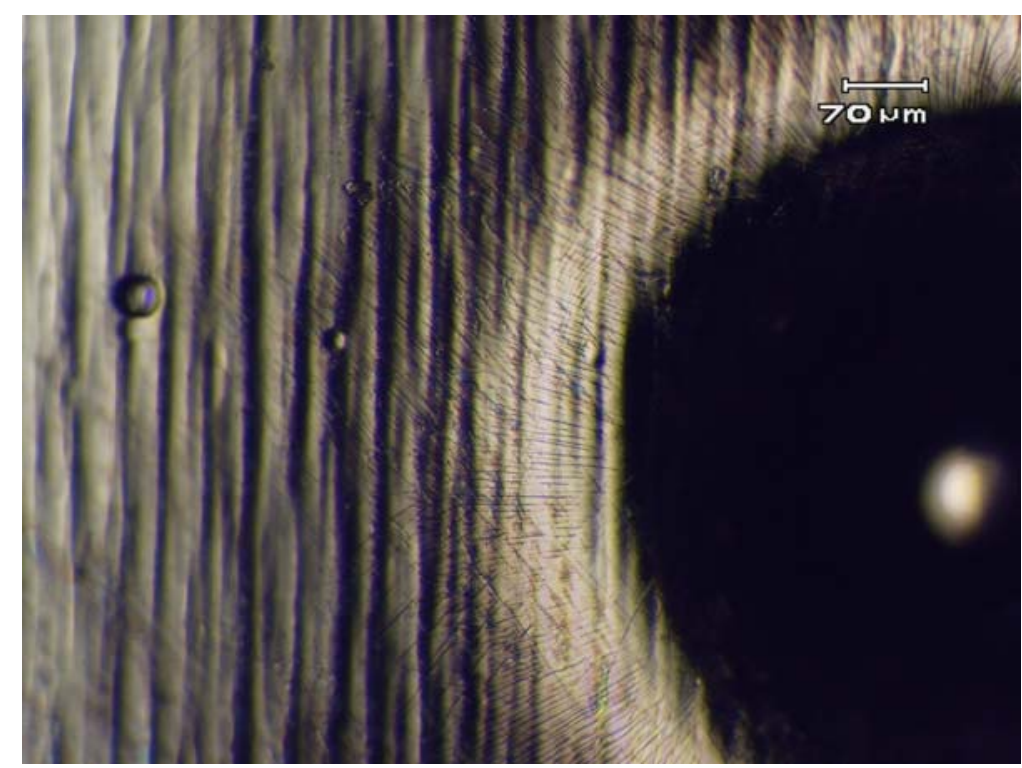

Figure 19: Micrograph of Rockwell C indent of commercially plated surface. Note the complete lack of delamination, despite the presence of small radial cracks in the plate.

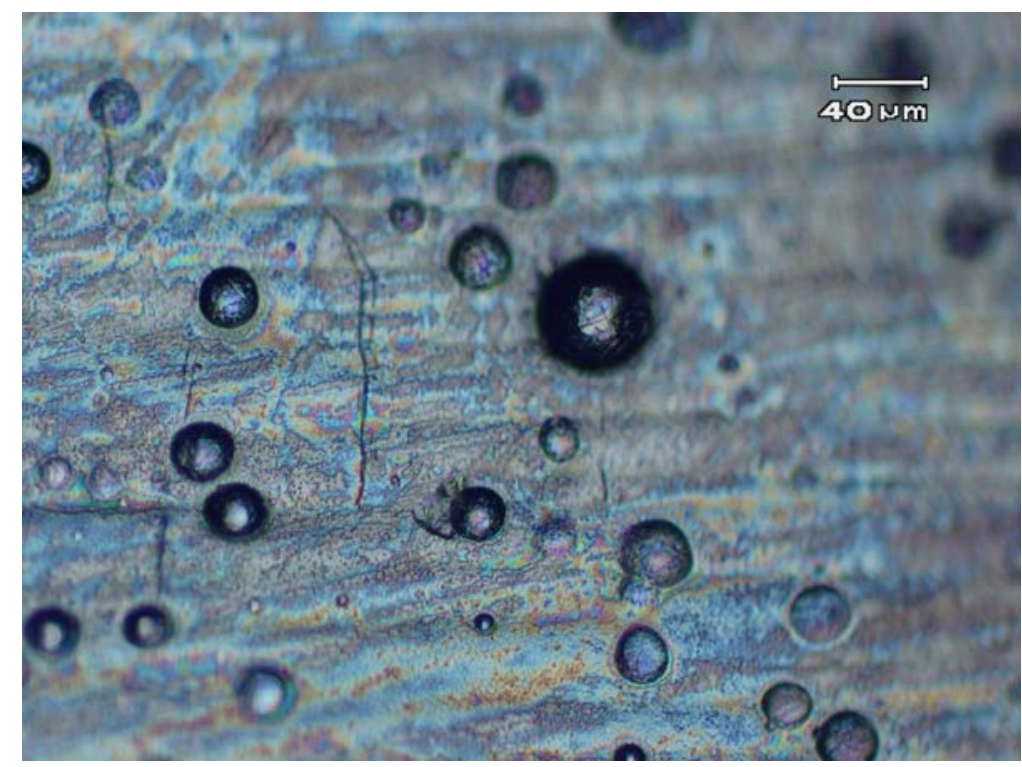

Figure 20: Micrograph of commercially plated surface showing imperfections from bubbles. 


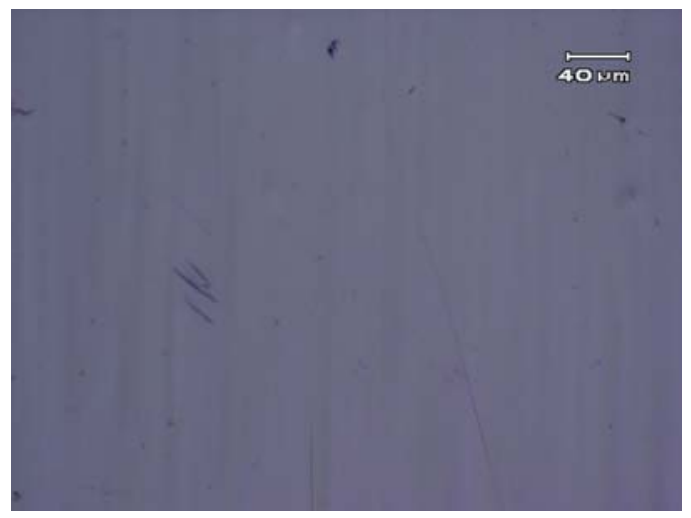

Figure 21: Micrograph of commercially plated surface after plating with surfactant bath.

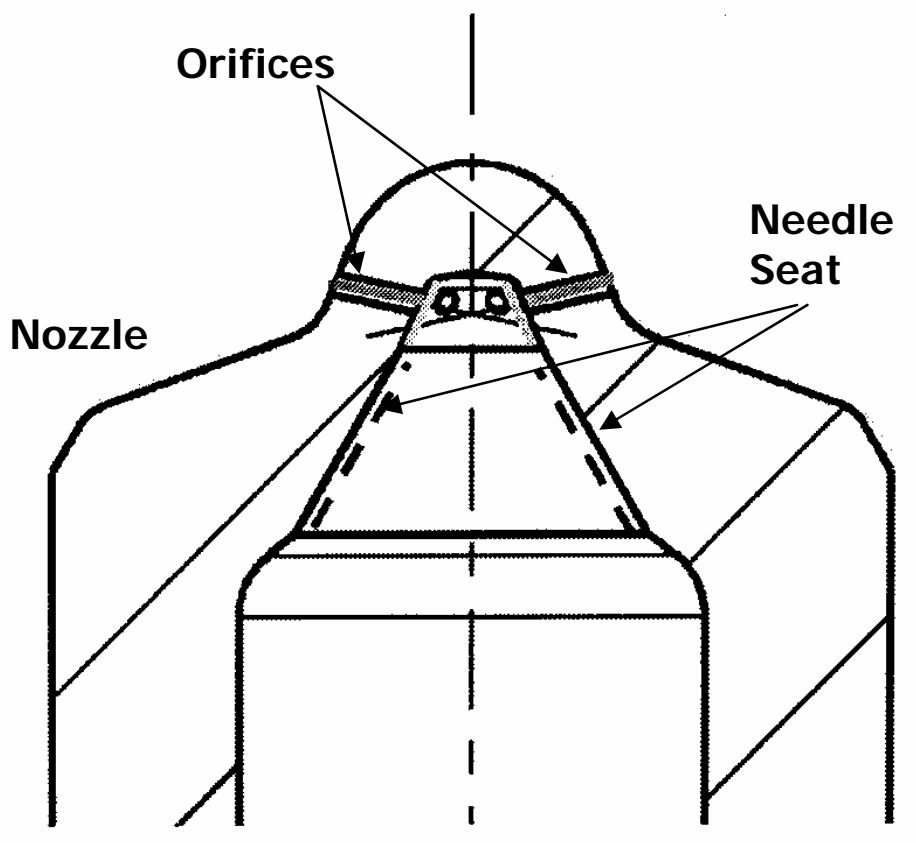

Figure 22: Schematic of sac-type nozzle interior showing needle seat (highlighted with dotted lines). (Schematic courtesy of Siemens AG.)

\footnotetext{
${ }^{1}$ L. M. Pickett and D. L. Siebers, "Orifice Diameter Effects on Diesel Fuel Jet Flame Structure," American Society of Mechanical Engineers, Internal Combustion Engine Division (Publication) ICE, 37(1), 2001, pp. 65-76.

${ }^{2}$ L. M. Pickett, D. L. Siebers, A. F. Morales, J. Hachman, and A. K. Sinensky, “An Investigation of Diesel Soot Formation Processes Using High Aspect Ratio Micro-Orifices," presented at HARMST 2003 HighAspect Ratio Micro-Structure Technology Workshop, Monterey, CA, 2003.

${ }^{3}$ R. Schaefer, EPA-NVFEL, private communication.

${ }^{4}$ John B. Heywood, Internal Combustion Engine Fundamentals, McGraw-Hill, New York, 1988.

${ }^{5}$ Glenn O. Mallory , "The Fundamental Aspects of Electroless Nickel Plating,"; in Electroless Plating:

Fundamentals and Applications, eds., Mallory, G. O. and Hajdu, J. B., American Electroplaters and Surface Finishers Society, 1991.
} 


\footnotetext{
${ }^{6}$ John J. Kuczma, "Equipment Design for Electroless Nickel Plating," in Electroless Plating: Fundamentals and Applications, eds., Mallory, G. O. and Hajdu, J. B., American Electroplaters and Surface Finishers Society, 1991.

${ }^{7}$ Rolf Weil and Konrad Parker, "The Properties of Electroless Nickel," in Electroless Plating: Fundamentals and Applications, eds., Mallory, G. O. and Hajdu, J. B., American Electroplaters and Surface Finishers Society, 1991.

${ }^{8}$ Brad Durkin, Mike Barnstead, and Boulos Marcos, "Basic Substrate Strategies and Approaches for Electroless Nickel," http://www.pfonline.com/articles/web0301.html.

${ }^{9}$ Juan Hajdu, "Surface Preparation for Electroless Nickel Plating,"; in Electroless Plating: Fundamentals and Applications, eds., Mallory, G. O. and Hajdu, J. B., American Electroplaters and Surface Finishers Society, 1991.

${ }^{10}$ J. B. Woodford, J. M. Perez, and G. R. Fenske, Argonne National Laboratory, unpublished results. ${ }^{11}$ See, e.g., ASTM G134-95(2001)e1, Standard Test Method for Erosion of Solid Materials by a Cavitating Liquid Jet, ASTM International, Philadelphia, PA, 2001.

${ }^{12}$ M. Factor and I. Roman, "Microhardness as a Simple Means of Estimating Relative Wear Resistance of Carbide Thermal Spray Coatings: Part 2. Wear Resistance of Cemented Carbide Coatings," J. Thermal Spray Tech. 11(4), 2002, pp. 482-495.
} 